Article

\title{
Study on Array Floating Platform for Wind Energy and Marine Space Optimization
}

\author{
Yi-Hung Chen and Ray-Yeng Yang *(i) \\ Department of Hydraulic and Ocean Engineering, National Cheng Kung University, Tainan 70101, Taiwan; \\ hank8637@gmail.com \\ * Correspondence: ryyang@mail.ncku.edu.tw
}

Citation: Chen, Y.-H.; Yang, R.-Y. Study on Array Floating Platform for Wind Energy and Marine Space Optimization. Sustainability 2021, 13, 14014. https://doi.org/10.3390/ su132414014

Academic Editor:

Majid Mohammadian

Received: 15 November 2021

Accepted: 14 December 2021

Published: 19 December 2021

Publisher's Note: MDPI stays neutral with regard to jurisdictional claims in published maps and institutional affiliations.

Copyright: (c) 2021 by the authors. Licensee MDPI, Basel, Switzerland. This article is an open access article distributed under the terms and conditions of the Creative Commons Attribution (CC BY) license (https:// creativecommons.org/licenses/by/ $4.0 /)$.

\begin{abstract}
The concept of multiline anchor, whose application is mainly considered in water depths beyond $100 \mathrm{~m}$ and analyzed only by numerical simulation, has been discussed for half a decade, yet previous studies have not conducted the wave basin experiment. Thus, this paper set this concept firstly with a shallow water mooring system designed for a Taiwan offshore water area, where the suitable water depth for floating offshore wind turbine is located from 50 to $100 \mathrm{~m}$, and then conducted a 1:144 scaled model wave basin experiment to validate the results from numerical simulation. In this paper, the numerical model simulated and analyzed three identical DeepCwind OC4 semi-submersible platforms equipped with NREL 5MW wind turbines in OrcaFlex and the experiment carried out by using three 1:144 scaled semi-submersible platforms with equivalent disks which simulated different operations of wind thrusts. To consider the possible influence of the wake effect, the minimum turbines spacing was set at $750 \mathrm{~m}$ in a full scaled model and the length of mooring lines was redesigned according to the catenary theory. This paper utilized OrcaWave to calculate hydrodynamic parameters and input it into OrcaFlex to simulate the line tension and the three degrees of freedom (surge, heave, and pitch) of the platforms under regular and irregular wave tests, and coordinate with scaled model tests carried out in Tainan Hydraulics Laboratory (THL). In addition to the reduction in the number of anchors, the concept of multiline anchor was also discussed in this study for the spatial configuration of offshore wind farms. It shows that the wind farm composed of three floating wind turbines can reduce the ocean space by roughly $24 \%$ compared to that with a single-line anchor. According to the comparison of numerical and experimental results, this study finally optimized the mooring lines by changing the diameter to increase the stability and the threshold of Minimum Breaking Load (MBL) and proposed a multiline anchor configuration for shallow offshore water area in Taiwan based on the results obtained.
\end{abstract}

Keywords: renewable energy; floating wind turbine; multiline anchor; space optimization; wake effect; experiment and numerical simulation

\section{Introduction}

In recent years, the offshore wind power industry has aggressively developed in many countries and the innovative technological concept of floating wind turbines seems fascinating, triggered by the depth limitations of fixed-foundation offshore wind turbines, which is roughly $50 \mathrm{~m}$. Although it is still possible to install fixed-foundation wind turbines in water depths above $50 \mathrm{~m}$, the cost of underwater foundations and the difficulty of construction will increase. Incidentally, the biggest difference between floating and fixed foundation wind turbines is that floating wind turbines do not have an underwater foundation. Instead, it is replaced by mooring lines and anchors. Floating wind turbines can be installed in deeper waters which contains higher wind potential than onshore areas and utilize relatively stable energy in the areas with strong potential in wind power to achieve higher efficiency. Most important of all, floating wind turbines can be pre-assembled in the harbor, which reduces the cost of ocean engineering construction. It is expected to be a 
key project for offshore wind development in Taiwan after 2025. At present, there are three major forms of platforms [1] developed globally (shown as Figure 1), which are separately spar, semi-submersible and tension leg platform.

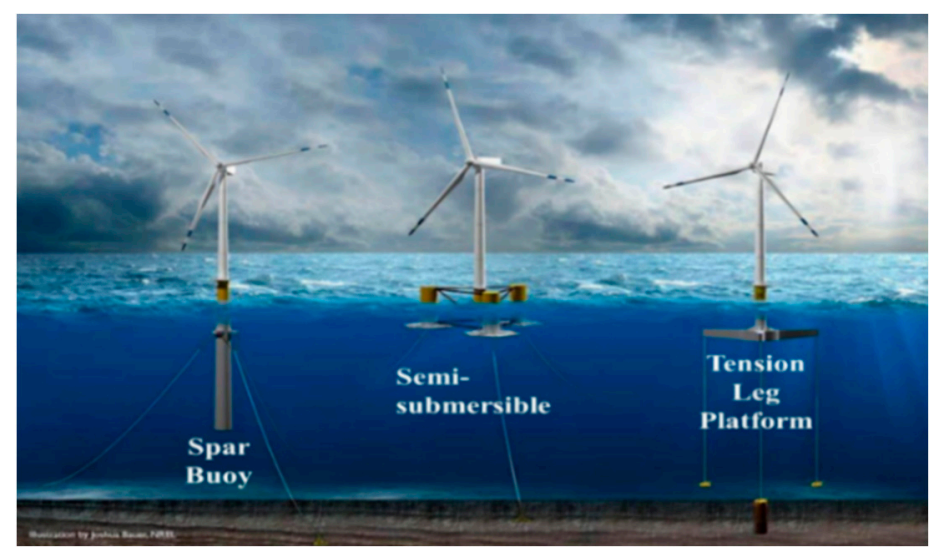

Figure 1. Three major different types of floating offshore wind turbines [1].

With the promotion of the offshore wind power industry, from offshore fixed foundations to floating wind turbines that are now developing, the world not only aims at constructing demonstration wind farms but hopes to build and provide enough stable electricity for neighboring residents. Moreover, when it comes to costs of floating offshore wind turbines, it is vital to ensure the distribution of the expenditures in every aspect. Even after plenty of studies, there is still a great deal of optimization to be achieved for floating offshore wind turbines and one significant obstacle in this floating system is the high capital expenditures (CAPEX) correlated with constructing the large platforms and mooring systems. With the large-scale of offshore floating wind turbines, the high capital cost of substructures, inclusive of floating platform, mooring lines and anchors, must be reduced if floating wind farms are to become competitive in the energy generation market in the future. Therefore, the goal of many countries has gradually changed from the stability of a single wind turbine towards the array arrangement of multiple wind turbines and how to save the cost of substructures including platform, anchors, and mooring lines [2-4]. Thus, Brain D. Diaz et al. [5] proposed a concept of coupled mooring systems in 2016 and investigated the cost saving potential and dynamic properties of shared catenary mooring systems that reduce both the number of lines and number of anchors in floating offshore wind farms. Although the study concluded the total system costs could be reduced, it also stated that displacements increase with the number of floaters, and cost savings diminish for larger numbers of turbines as the required diameters, lengths and costs of mooring chains increase. In addition, in array arrangements of floating offshore wind turbines, the distance between wind turbines should take the impact of wake loss into the account. Then, the concept of multiline anchor was further analyzed by Casey Fontana [6,7] and was mainly used in floating wind turbine platforms. The anchor is used to connect multiple mooring lines (as shown in Figure 2) to save the cost of anchors in the wind farm. Currently, most floating wind turbines are set up in the water depths between 100 and $200 \mathrm{~m}$; therefore, Casey's research focused on deep water, and FAST is used to simulate the force of the mooring line at a multiline anchor point. To testify whether this concept can be also applied to the shallow waters (50 to $100 \mathrm{~m}$ ) off the coast of Hsinchu areas in Taiwan, this paper sets the multiline anchor at a water depth of about $70 \mathrm{~m}$, redesigns the length of the mooring lines and the horizontal distance between the adjacent wind turbines and analyzes the motion of platforms and the line tension of the multiline anchor. Even though farther offshore areas possess higher wind potential, it is still crucial to optimize the space programming and reduce the capital expenditures of wind farm for a limited area such as Taiwan. Thus, this study focused on the difference of motion between the platforms and tension of multiline anchor in shallow water (70 m water depth). After the design of 
a shallow water mooring line system, three OC4 DeepCwind platforms combined with NREL 5 MW wind turbines were carried out in numerical simulation (OrcaFlex) and 1:144 scaled model experiment. After mutual verification, many good trends of agreement were obtained between them and, therefore, optimization of the mooring line design can be further implemented in numerical simulation to improve the stability and feasibility of multiline anchor system. Therefore, according to the comparison of numerical and experimental results, this study finally optimized the mooring lines by changing the diameter to increase the stability and the threshold of Minimum Breaking Load (MBL) and proposed a multiline anchor configuration for shallow offshore water area in Taiwan based on the results obtained in this study.

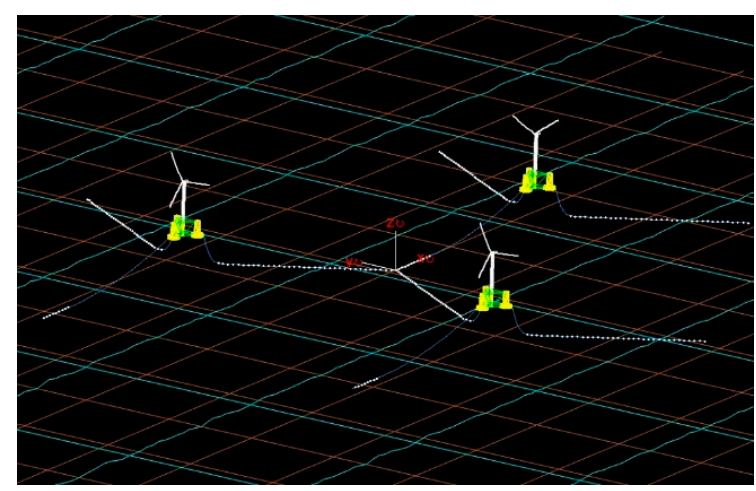

Figure 2. Sketch of Multiline anchor system.

\section{Space Optimization of Multiline Anchors and Shallow Water Mooring Design}

Multiline anchor is a concept that an anchor connects with more than one mooring line and the effectiveness depends on the number of mooring lines and anchors. By using different types of floating wind turbines, there are also multiple choice of configuration of array wind turbines. Figure 3 shows the utilization of multiline anchors with different type of floating wind turbines.

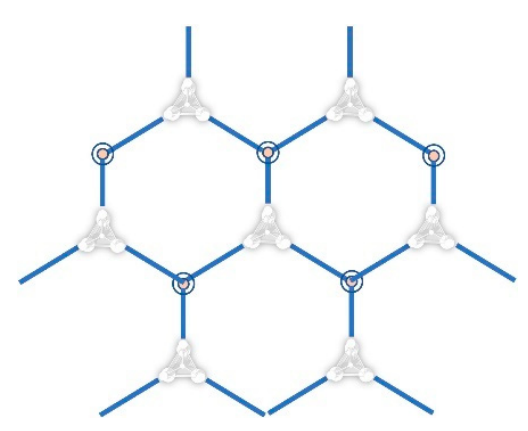

(a)

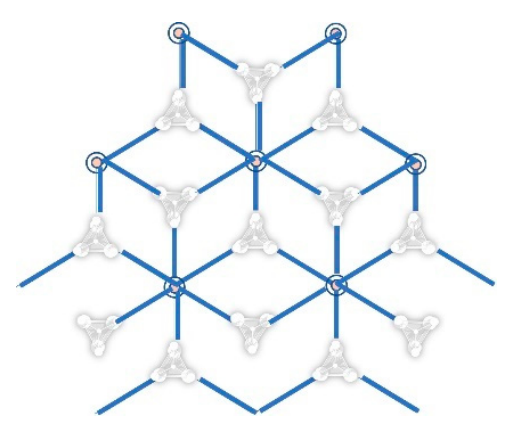

(b)

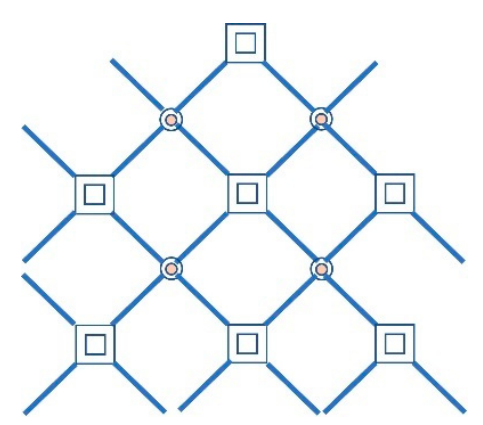

(c)

Figure 3. Different configuration of multiline anchor (double circle represents sharing anchors). (a) Sharing anchors connected with three mooring lines (Semi-submersible type) (b) Sharing anchors connected with six mooring lines (Semisubmersible type) (c) Sharing anchors connected with four mooring lines (Barge type).

If there are 100 floating wind turbines in a wind farm, three-line anchor, six-line anchor, and four-line anchor can reduce 60, 79, and 70 percent of anchors, respectively. Although there is no area large enough to accommodate hundreds of wind turbines, it can still reduce the costs of substructures in specified quantity. It is also vital that cost reduction of mooring system builds on reasonable distance between floating offshore wind turbines. In Casey's research [8,9], the NREL 5MW wind turbine on OC4 semi-submersible platform was selected in the numerical model which focused on the resultant force acting on the anchor. The results of simulation concluded that when comparing with the single-line 
anchor, the multiline anchor can decrease by $16 \%$ in the three-line anchor and increase by $20 \%$ in the six-line anchor for an operated condition, and decrease by $11 \%$ in the three-line anchor and increase by $10 \%$ in the six-line anchor for the extreme condition (parking). Therefore, based on the above experience, the three-line multiline anchor was also selected in this paper.

After adopting the concept of multiline anchors, it not only decreases the number of anchors but the area of wind farm, which is beneficial to the configuration of offshore wind farm. Figure 4 shows that multiline anchor decreases the radius from $838 \mathrm{~m}$ to $750 \mathrm{~m}$ in a wind farm which is composed of three floating wind turbines. The area of single anchor and multiline anchor is, respectively, 2.21 and 1.66 million square meters, which represents an area reduction of about $24.4 \%$.
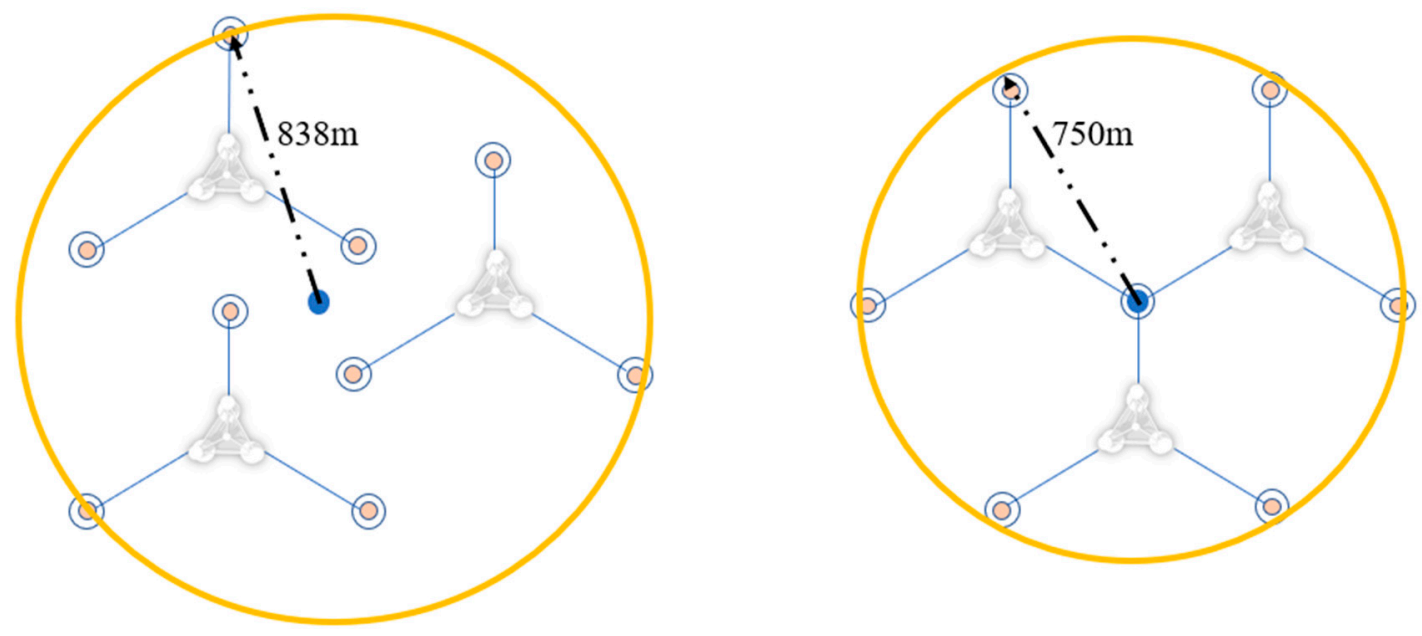

Figure 4. Sketch of single anchor (left) and multiline anchor (right).

There are three different distances $(6 \mathrm{D}, 8 \mathrm{D}, 10 \mathrm{D})$ between three platforms shown in Table 1 . The area reduces around $24 \%$ regardless of the distances. This result is based on the same distance between platforms by single anchor and multiline anchor; however, in reality, the configuration of single anchor might be different from that in Figure 4, which causes a wind farm to occupy a greater land area.

Table 1. Area reduction of multiline anchors.

\begin{tabular}{|c|c|c|c|}
\hline \multirow[t]{2}{*}{ Distance between Three Platforms } & \multicolumn{2}{|c|}{$\begin{array}{l}\text { Diameter of a Wind Turbine (D) } \\
\text { (From Center to the Farthest Anchor Position) }\end{array}$} & \multirow[t]{2}{*}{ Area Reduction (\%) } \\
\hline & Single Anchor & Multiline Anchor & \\
\hline $6 \mathrm{D}$ & $6.69 \mathrm{D}$ & $6 \mathrm{D}$ & 24.40 \\
\hline $8 \mathrm{D}$ & $8.92 \mathrm{D}$ & $8 \mathrm{D}$ & 24.41 \\
\hline $10 \mathrm{D}$ & $11.15 \mathrm{D}$ & 10D & 24.41 \\
\hline
\end{tabular}

According to the Offshore Wind Power Project Environmental Impact Statement from the Preparatory Office of Taiwan First Wind Power Co., Ltd., Taipei, Taiwan [10], areas suitable for floating wind platforms in Taiwan are within a water depth from 70 to $95 \mathrm{~m}$. However, in the shallow water (50 to $100 \mathrm{~m}$ water depth), mooring lines cannot be shortened in proportion to water depth because the restoring force provided by the suspended lines has decreased. The mooring lines are divided into two parts in the sea, the suspended line and the touchdown section which lays down on the seabed, and the former is the part that maintains the floater by its own weight. When the floater connected with the mooring line moves forwards, the touchdown part will be pulled up. However, the circumstances of shallow (50 to $100 \mathrm{~m}$ ) and deep $(200 \mathrm{~m}$ ) water are totally different because the suspended line is much shorter in the shallow water. By adopting the catenary theory, 
we can obtain the length of mooring lines within a range of four to eight times water depth (Figure 5) and, therefore, the length of mooring lines in $70 \mathrm{~m}$ water depths will be selected as $420 \mathrm{~m}$ (six times the water depth) [11-13] in order to fit the distance between platforms. The distances between floating wind turbines in a wind farm (water depth is beyond $100 \mathrm{~m}$ ) are large enough to neglect the effect of diffraction and radiation and, therefore, this paper investigated not only tension of the multiline anchor but also the effect between platforms via numerical simulation and 1:144 scaled-down model experiment. The motion of the floating platforms and force of mooring lines has also been analyzed in this paper and inspected whether they meet design conditions and limitations of the certification.

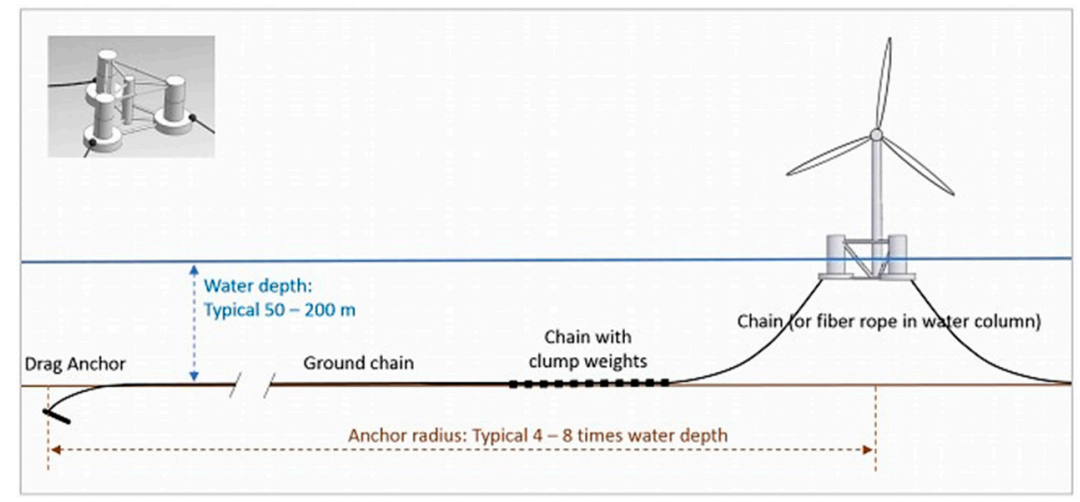

Figure 5. Typical Shallow Water Mooring [12].

Previous research has utilized the concept of multiline anchor in deeper water (water depth is set to be $200 \mathrm{~m}$ and $100 \mathrm{~m}$ ) in other numerical simulation and calculated the reduction in the number of anchors in an offshore wind farm. However, this study has roughly measured the reduction in wind farm area and applied the multiline anchor concept in a Taiwan offshore water area to assess whether it is feasible in relatively shallow water conditions (which is $70 \mathrm{~m}$ water depth) by numerical simulation and wave basin experiment. Thus, the following configuration of this paper is as follows. Section 3 introduces the numerical model of the floating wind turbines and the mooring system. Section 4 includes the numerical simulation and experimental set-up. Section 5 presents the comparison between the experiment and numerical simulation. Section 6 discusses the main findings and conclusions.

\section{Numerical Simulation Method}

OrcaWave [14] is a diffraction analysis program which applies potential flow theory to calculate forces and response for rigid bodies due to surface water waves and can input the RAO and QTF in OrcaFlex for coupling forces and motions. OrcaFlex [15] is a numerical simulation software, developed by Orcina, and widely applied to various analysis including mooring dynamics in offshore marine systems, dynamic analysis of riser system and different floating platforms.

\subsection{Governing Equation}

The governing equation of a floater is comprised of wind, wave, current and mooring line.

$$
\overrightarrow{F_{\text {wave }}}+\overrightarrow{F_{\text {wind }}}+\overrightarrow{F_{\text {mooring }}}+\overrightarrow{F_{\text {current }}}=\vec{M} \cdot \vec{a}
$$

$\overrightarrow{F_{\text {wave }}}$ represents wave loads acting on floaters, $\overrightarrow{F_{\text {wind }}}$ represents the wind loads, $\overrightarrow{F_{\text {mooring }}}$ represents the loads of the mooring system, and $\overrightarrow{F_{\text {current }}}$ represents the current loads. $\vec{M}$ is composed of $m$ and $M_{a}$ which are mass and added mass of the floater.

Moreover, the $\overrightarrow{F_{\text {wave }}}$ is calculated by the potential flow theory, which is comprised of incident wave $\left(\Phi_{I}\right)$, radiation $\left(\Phi_{R}\right)$, and diffraction potential $\left(\Phi_{D}\right)$. Generally, the velocity potential $(\Phi)$ proceeds with perturbation expansion and first and second order are more 
tractable, which results in the solution of "Response Amplitude Operator (RAO), added mass and damping" and "Quadratic Transfer Functions (QTFs)".

$$
\Phi=\Phi_{1}+\Phi_{2}+\ldots=\Phi_{I}+\Phi_{R}+\Phi_{D}
$$

The governing equation is then presented as:

$$
\begin{aligned}
& \left\{m+M_{a}\right\} a(t)+c v(t)+B|v(t)| v(t)+K x(t) \\
& \quad=F_{\text {wind }}+F^{1 s t}(t)+F^{2 n d}(t)+F_{\text {mooring }}(t)+F_{\text {current }}(t)
\end{aligned}
$$

where

$F_{\text {wind }}$ is the aerodynamic load on wind turbine and tower.

$F^{1 s t}(t)$ is the first order wave excitation force.

$F^{2 n d}(t)$ is the second order wave excitation force.

$F_{M}(t)$ is the mooring force.

$c$ is the linear damping matrix including the drift damping effects

$B$ is the quadratic damping matrix.

$K$ is the total stiffness matrix.

$x(t), v(t)$ and $a(t)$ represent separately the displacement, velocity, and acceleration time-series vectors in six degrees of freedom.

\subsection{Wind Load}

Wind loads act on two components of the floating wind turbine, which are the blades and the tower. However, OrcaFlex can only calculate the loads by potential flow and BEM rather than the actual flow such as Computational Fluid Dynamics (CFD) software. Blade Element Momentum (BEM) is adapted from AeroDyn v15.04 [16]. As for the tower, potential theory employs the classical analytic solution to potential flow around a cylinder and the effect of tower's influence will be added into the aerodynamic load in governing equation.

\subsection{Mooring Load}

In OrcaFlex, a finite element model is used for a mooring line as shown in Figure 6. A line is represented by a lumped mass method [17]. That is, a line is divided into a series of segments which are modelled by straight massless model with a node at each end. The model segments only model the axial and torsional force of the line and thus can be considered as being comprised of two co-axial flexible rods that are connected by axial and torsional spring-dampers.

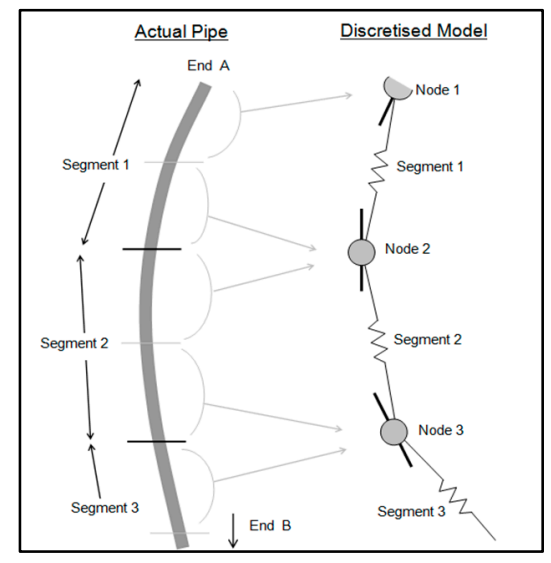

Figure 6. FEM and lumped mass method. 


\section{Numerical and Experimental Model Set Up \\ 4.1. Model Set-Up}

The mooring system has adopted catenary type, and the platform has chosen the OC4 semi-submersible [18] (Offshore Code Comparison Collaboration Continuation) which was a continuation of OC3 project. Firstly, the semi-submersible type of floating wind turbines needs to be set up in the model and there is an example of OC4 DeepCwind semi-submersible which is provided by the Orcina company. Table 2 shows the properties of wind turbines (NREL 5MW), and Table 3 shows the overview of the semi-submersible platform. There are three identical platforms in the model to set-up the multiline anchor, and thus Table 4 shows the properties of the whole mooring system in the wind farm. The configuration of wind farm is shown in Figure 7.

Table 2. Properties of the wind turbine [18].

\begin{tabular}{ccc}
\hline Property & Values & Unit \\
\hline Wind turbine capability & 5 & $\mathrm{MW}$ \\
Blade & 3 & - \\
Rotor diameter & 126 & $\mathrm{~m}$ \\
Cut-in, rated, cut-out wind speed & $3,11.4,25$ & $\mathrm{~m} / \mathrm{s}$ \\
Rotor weight & 110.00 & te \\
Nacelle weight & 240.00 & te \\
Tower weight & 347.46 & te \\
\hline
\end{tabular}

Table 3. Properties of the semi-submersible platform [18].

\begin{tabular}{ccc}
\hline Property & Values & Unit \\
\hline Depth of platform base below SWL (total draft) & 20 & $\mathrm{~m}$ \\
Elevation of the main column (tower base) above SWL & 10 & $\mathrm{~m}$ \\
Elevation of offset columns above SWL & 12 & $\mathrm{~m}$ \\
Spacing between offset columns & 50 & $\mathrm{~m}$ \\
Length of upper columns & 26 & $\mathrm{~m}$ \\
Length of base columns & 6 & $\mathrm{~m}$ \\
Depth to top of base columns below SWL & 14 & $\mathrm{~m}$ \\
Diameter of the main column & 6.5 & $\mathrm{~m}$ \\
Diameter of offset (upper) columns & 12 & $\mathrm{~m}$ \\
Diameter of base columns & 24 & $\mathrm{~m}$ \\
Diameter of pontoons and cross braces & 1.6 & $\mathrm{~m}$ \\
Platform mass, including ballast & $1.3473 \times 10^{7}$ & $\mathrm{~kg}$ \\
CM location below SWL & 13.46 & $\mathrm{~m}$ \\
\hline
\end{tabular}

Table 4. Properties of the mooring system.

\begin{tabular}{ccc}
\hline Property & Values & Unit \\
\hline Number of mooring lines & 9 & - \\
Angle between adjacent lines & 120 & $\circ$ \\
Depth to anchors below sea water level & 70 & $\mathrm{~m}$ \\
Depth to fairleads below sea water level & 14 & $\mathrm{~m}$ \\
Radius of anchors from platform centreline & 433 & $\mathrm{~m}$ \\
Radius to fairleads from platform centreline & 40.87 & $\mathrm{~m}$ \\
Unstretched mooring line length & 420 & $\mathrm{~m}$ \\
Mooring line diameter & 0.095 & $\mathrm{~m}$ \\
Equivalent mooring line mass in water & 179.59 & $\mathrm{~kg} / \mathrm{m}$ \\
Distance between floating platforms & 750 & $\mathrm{~m}$ \\
\hline
\end{tabular}

After deciding the distance between wind turbines and redesigning the length of mooring lines, the next step is to input the parameters into OrcaWave, such as distance between platforms, water depth, water density, center of gravity, and moment of inertia, 
etc. The wave range is from 0 to 180 degrees every 22.5 degrees and the period range is from 1 to $30 \mathrm{~s}$ with 1 second intervals.

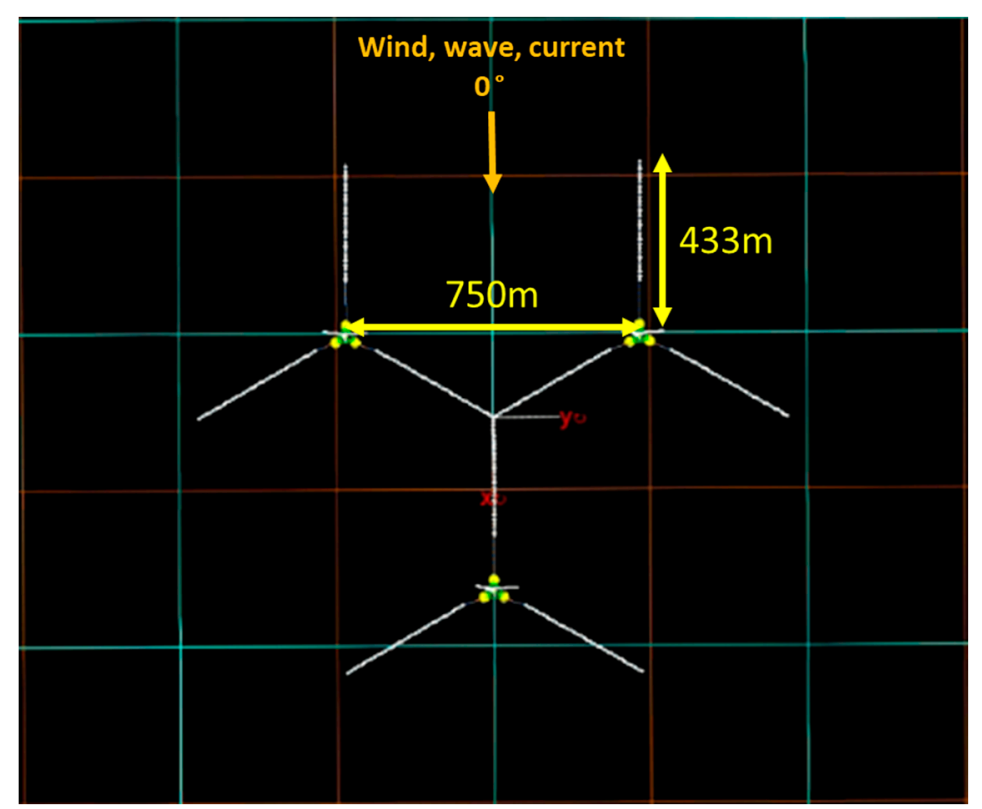

Figure 7. Configuration of three OC4 floating wind turbines and mooring system.

Then, the hydrodynamic parameters are imported into the vessel type of OrcaFlex, and the whole mooring system including the diameter and length of mooring lines and anchor points, which are merely a fixed point in simulation, is set up (shown in Figure 6). This thesis sets up two parts which are regular wave and irregular wave tests, the former is to compare the motion between front and rear platform and the latter is to simultaneously observe the motion and the feasibility of mooring design under extreme conditions in the western Taiwan offshore area. Incidentally, the period of regular wave test includes 12 to $30 \mathrm{~s}$, and the conditions will compare with the results from experiment. The wave direction for all sets are as 0 degree and simulation time in regular and irregular wave are, respectively, 1800 and $7200 \mathrm{~s}$. The wind speed is $60 \mathrm{~m} / \mathrm{s}$ according to IEC (International Electrotechnical Commission) Class T [19] (Typhoon Class $57.5 \mathrm{~m} / \mathrm{s}$ ), and the current speed set as $1.2 \mathrm{~m} / \mathrm{s}$. The flowchart of numerical simulation is shown in Figure 8 .

(RAO, $1^{\text {st }} \& 2^{\text {nd }}$ order)

Set-up model (three platforms)

(water depth :70 m)
Input into OrcaWave (hydrodynamic parameters)

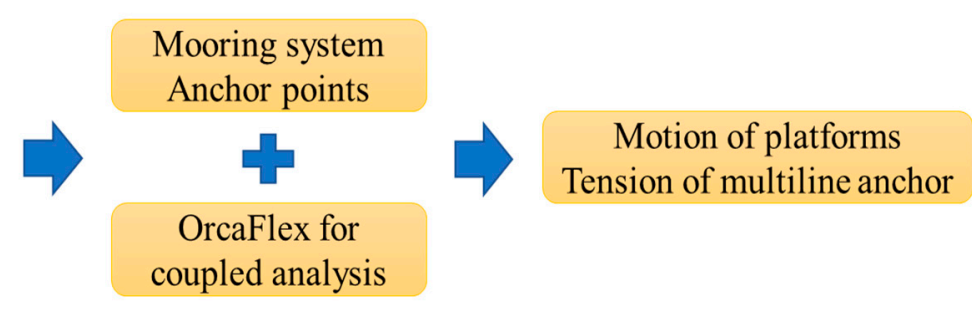

(Wind, wave, current)

Figure 8. The flowchart of numerical simulation.

\subsection{Experimental Model and Equipment}

The wind, wave, and current test of three identical OC4 semi-submersible models was implemented at the wave basin in Tainan Hydraulics Laboratory (THL), National Cheng Kung University (NCKU). The wave basin has a water depth of $1.2 \mathrm{~m}$, length and width are, respectively, $60 \mathrm{~m}$ and $7 \mathrm{~m}$ (Figure 9). In the model test, there are two crucial parameters in the model test which are the Froude number and Reynolds number; the former is the ratio between inertia and gravity, and the latter is the ratio between inertia and viscous forces. However, it is impossible to simultaneously satisfy the Froude number 
and Reynolds number between the model and its full-scale structure in a scaled model experiment. For instance, Reynolds law of similarity will be adopted when considering the wind turbine due to the viscosity and inertia force of the blade aerodynamics. On the other hand, the Froude law of similarity is adopted by the offshore structure to satisfy the gravity and inertia force from the wave field. In fact, the wave forces acting on the platform have greater influence than wind force because, in this experiment, the main measuring items are natural frequency, RAO of the platform and the tension of mooring lines. Therefore, the Froude law of similarity is applied to this floating offshore wind turbine model test in the scale ratio of 1 to 144 and the effect of aerodynamics is through the scaled down thrust. The conducted experiments were composed of a free decay test, regular wave test, and irregular wave test (with wind and current).

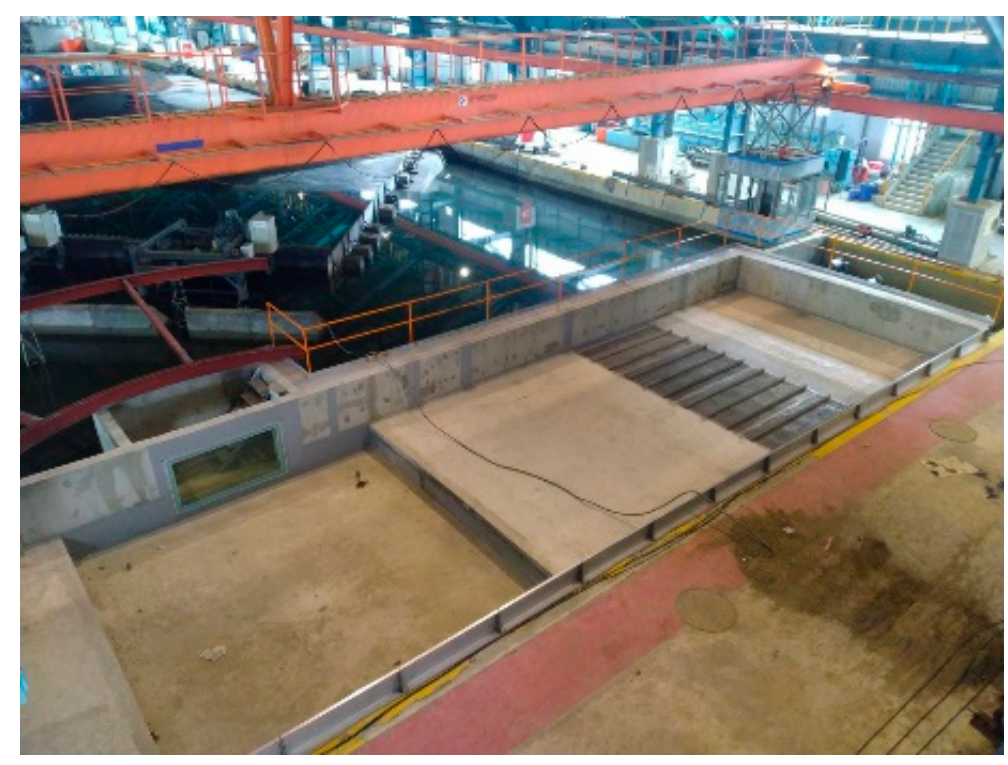

Figure 9. Photo of wave basin $(60 \mathrm{~m} \times 7 \mathrm{~m} \times 1.2 \mathrm{~m})$ in the THL, NCKU.

Owing to the importance of hydrodynamic loads in this paper, the law of similarity of the Froude number was applied to the scaled model test. It is worth mentioning that the aerodynamic loads cannot be met in this experiment. Therefore, the wind turbine has been replaced by an equivalent disk to simulate the thrust caused by the wind effect.

There are two main steps before conducting the experiment. The first step is to ensure the accuracy of the models (Figure 10) including the mass, ZCG (center of gravity) of the platform (shown in Table 5) by comparing the full scaled and 1:144 scaled model of the semi-submersible platforms, and the second part is the mooring system.

Table 5. Specification comparison between prototype and experimental model.

\begin{tabular}{|c|c|c|c|c|}
\hline $\begin{array}{ll}\text { Specification } & \text { Platform } \\
\end{array}$ & Prototype & 1/144 Model & Measured & Error $(\%)$ \\
\hline Diameter of Main column & $6.5(\mathrm{~m})$ & $4.5(\mathrm{~cm})$ & $4.4(\mathrm{~cm})$ & 2.22 \\
\hline Center of gravity & $6.54(\mathrm{~m})$ & $4.542(\mathrm{~cm})$ & $4.5(\mathrm{~cm})$ & 0.93 \\
\hline Draft & $20(\mathrm{~m})$ & $13.89(\mathrm{~cm})$ & $13.8(\mathrm{~cm})$ & 0.64 \\
\hline Diameter/Height of upper pontoons & $12 / 26(\mathrm{~m})$ & $8.3 / 18.1(\mathrm{~cm})$ & $8.2 / 18.3(\mathrm{~cm})$ & $1.20 / 1.10$ \\
\hline Diameter/Height of bottom pontoons & $24 / 6(\mathrm{~m})$ & $16.6 / 4.2(\mathrm{~cm})$ & $16.6 / 4.5(\mathrm{~cm})$ & $0 / 7.14$ \\
\hline Height of the tower & $77.6(\mathrm{~m})$ & $53.9(\mathrm{~cm})$ & $55.3(\mathrm{~cm})$ & 2.6 \\
\hline Mass (without tower) $(\mathrm{kg})$ & $1.3473 \times 10^{7}$ & 4.512 & 4.510 & 0.04 \\
\hline Mass (with tower) (kg) & $1.4073 \times 10^{7}$ & 4.713 & 4.721 & 0.17 \\
\hline
\end{tabular}

In a scaled-model experiment, it is important to measure the tension of mooring lines. The stiffness of the mooring line can be theoretically divided into two different parts [11], 
the geometry and the elastic stiffness, the former is provided by the self-weight of mooring lines and the latter is provided by the line elongation when the mooring lines become taut. To design mooring lines in the experiment, the mooring line model was firstly needed to scale down the relation chart of the surge displacement and restoring force which can be obtained from the prototype mooring. In the chart, the part which restoring force increases relatively slowly replaces with corresponding chain and the part which restoring force increases rapidly replaces with the spring. The spring constant $(\mathrm{k})$ needs to match the slope of the latter part and it is calculated as $0.3412 \mathrm{~N} / \mathrm{cm}$. (Figure 11) Owing to the small scale in this study, the mooring line in experiment has been modified and is shown in Table 6.
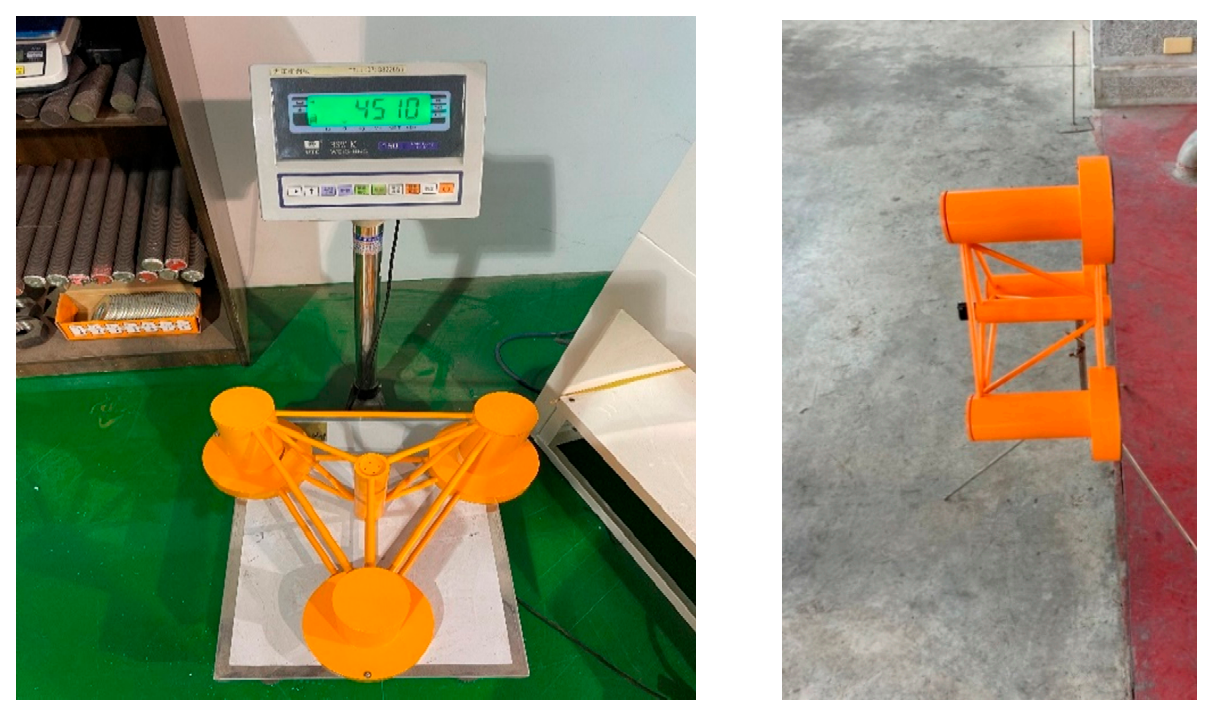

Figure 10. Calibration of the 1:144 scaled experimental model.

Table 6. Properties of mooring system in numerical simulation and experiment.

\begin{tabular}{ccc}
\hline & Numerical Simulation & $\begin{array}{c}\text { Experiment } \\
\text { (1/144 Model) }\end{array}$ \\
\hline Number of Anchors & 7 & 7 \\
Water Depth & $70 \mathrm{~m}$ & $0.5 \mathrm{~m}$ \\
Depth to fairlead below SWL & $14 \mathrm{~m}$ & $0.1 \mathrm{~m}$ \\
Radius to Anchor from Platform Centerline & $433 \mathrm{~m}$ & $3 \mathrm{~m}$ \\
Unstretched Mooring Line Length & $420 \mathrm{~m}$ & $2.7 \mathrm{~m}$ \\
Diameter of Mooring Lines & $95 \mathrm{~mm}$ & $3 \mathrm{~mm}$ \\
Equivalent Mooring Line Unit Weight & $179.6 \mathrm{~kg} / \mathrm{m}$ & $0.158 \mathrm{~kg} / \mathrm{m}$ \\
\hline
\end{tabular}
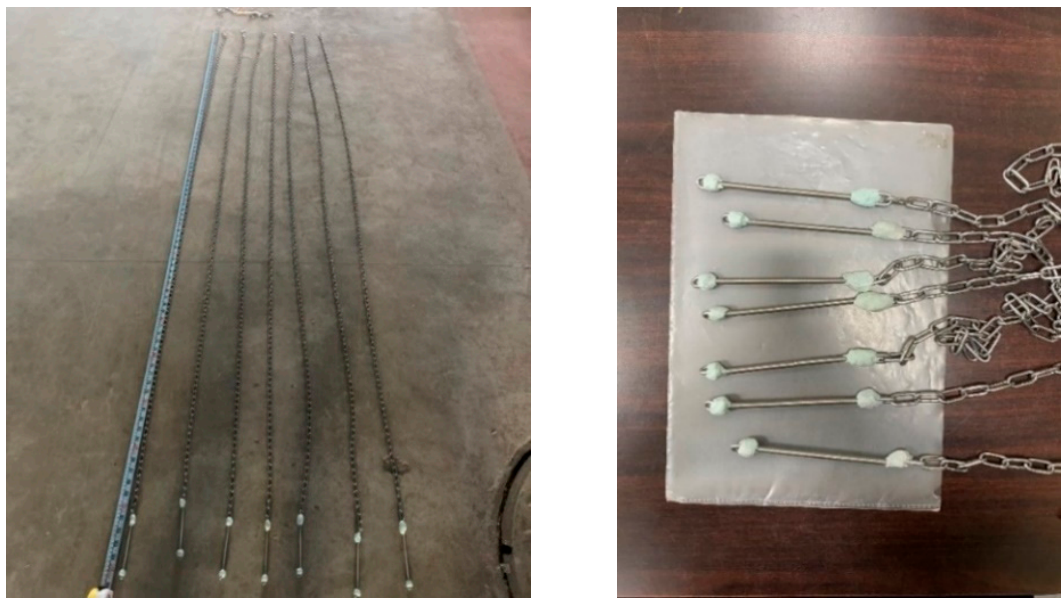

Figure 11. Experimental mooring line. 
In the experiment, the wind force was simulated by the equivalent disks (Table 7) which being calculated through the 1:144 scaled down thrust from NREL 5MW wind turbines by MIRDC (Metal Industries Research \& Development Centre) and thus there were two different diameters of disks (Figure 12) which representing the wind forces caused by $11.4 \mathrm{~m} / \mathrm{s}$ (rated speed) and $60 \mathrm{~m} / \mathrm{s}$ (class T), respectively. Under $11.4 \mathrm{~m} / \mathrm{s}$ wind speed, a disk larger than $60 \mathrm{~m} / \mathrm{s}$ is needed since the thrust is highest at the rated speed.
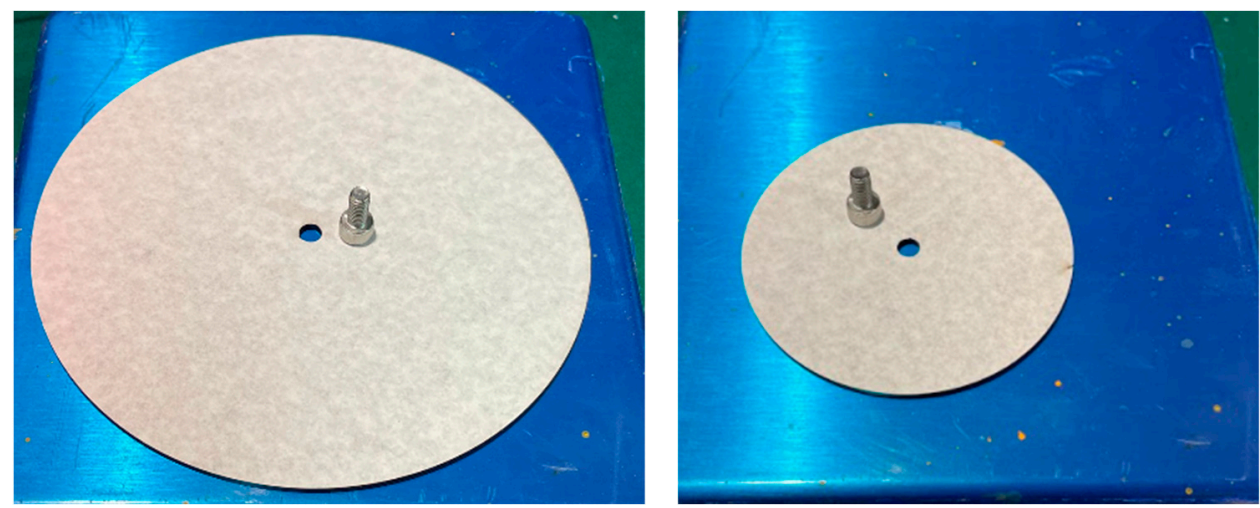

Figure 12. Equivalent disk for different wind conditions (left: $11.4 \mathrm{~m} / \mathrm{s}$, right: $60 \mathrm{~m} / \mathrm{s}$ ).

Table 7. Diameter of equivalent disk under different wind speed.

\begin{tabular}{cccccc}
\hline Full Scale & $\begin{array}{c}\text { Wind Speed in } \\
\text { Simulation }(\mathbf{m} / \mathbf{s})\end{array}$ & $\begin{array}{c}\text { Thrust in } \\
\text { Simulation } \mathbf{( k N )}\end{array}$ & $\begin{array}{c}\mathbf{1 : 1 4 4} \text { Scaled Wind } \\
\text { Speed }(\mathbf{m} / \mathbf{s})\end{array}$ & $\begin{array}{c}\mathbf{1 : 1 4 4} \text { Scaled Thrust } \\
\mathbf{( N )}\end{array}$ & $\begin{array}{c}\text { Diameter of Disk } \\
(\mathbf{c m})\end{array}$ \\
\hline 1 & 11.4 & 790 & 5 & 0.26 & 13.53 \\
1 & 60 & 280 & 5 & 0.10 & 8.05 \\
\hline
\end{tabular}

In the wave basin, there are wave, wind (Figure 13), and current generators to simulate the sea conditions in experiments. Figures 14-16 show the sensors used to measure the wave height, wind speed, and current speed, which are for the calibration of the conditions. Figure 17 is tensiometer which connected with mooring lines to measure the tension on the fairlead. Figure 18 is gyroscope which was put on the platform to measure its rotation angle, and Figure 19 is a LED tracing system which was fixed to the side and back platform and tracked by the camera, and it can track the displacement of the platform, including surge and heave. Finally, the top view configuration of the experimental set-up is shown in Figure 20. The resultant forces on the multiline anchor were measured by the tension-meter and the pitch of rear and front platforms are measured by gyroscopes which are fixed near the center of gravity. However, the LED tracking system was only put on the rear platforms due to space limitation of equipment and wave basin since the LED needs at least two cameras to capture the motion of heave and surge.

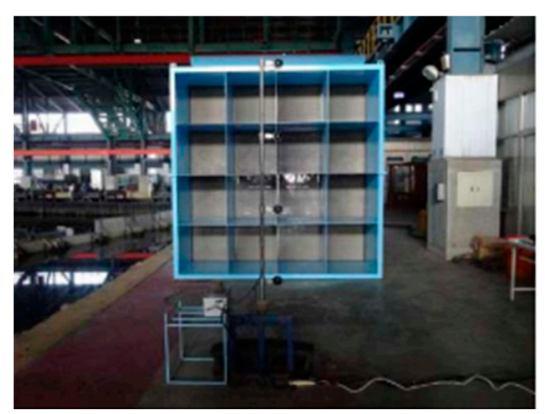

Figure 13. Wind generator system. 


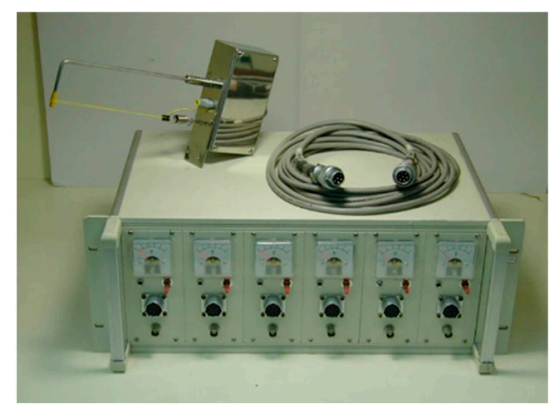

Figure 14. Capacitance-type wave gauge.

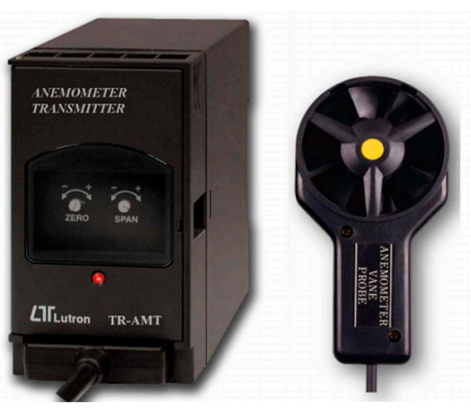

Figure 15. Anemometer.

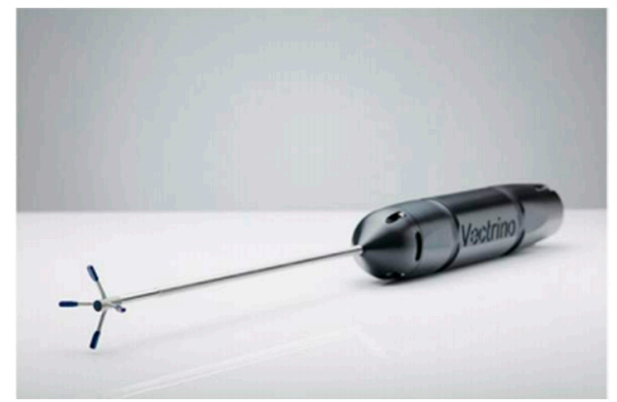

Figure 16. Velocimeter.

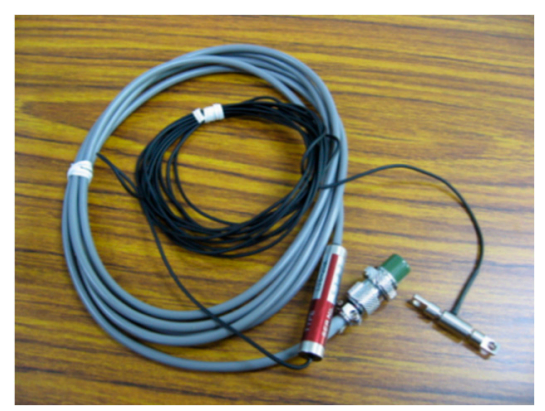

Figure 17. Tensiometer.

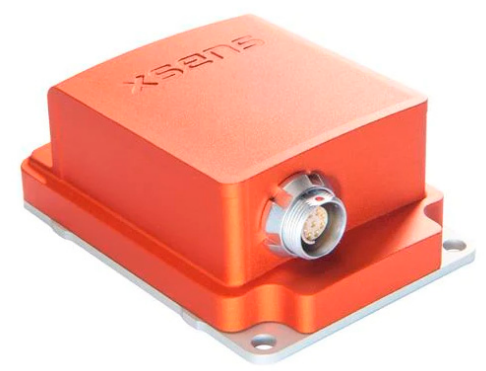

Figure 18. Gyroscope. 

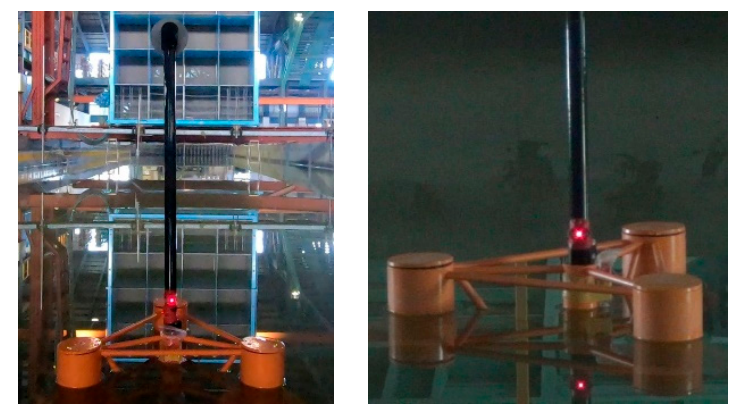

Figure 19. LED on the platform (side and backwards).
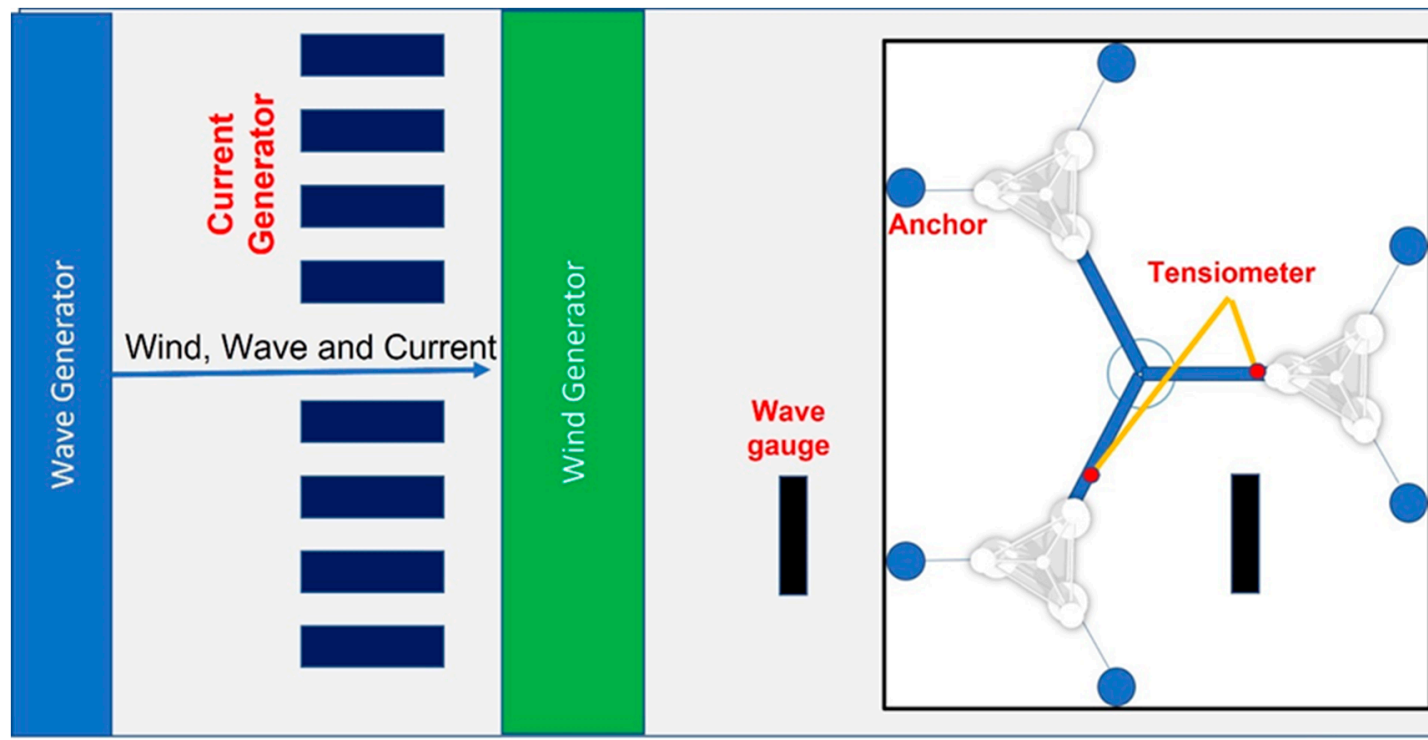

\section{하}

Camera

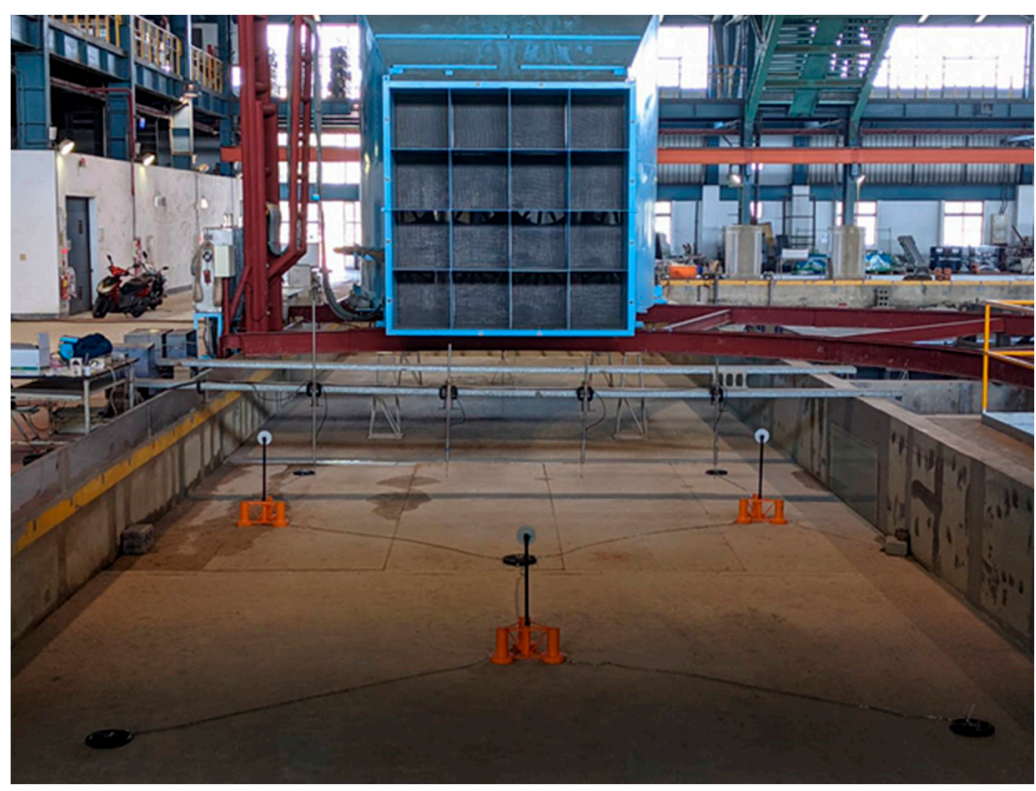

Figure 20. Configuration of experimental set-up. 


\subsection{Premiere Test of Free-Decay}

After checking the characteristics of platforms, free-decay test is conducted to measure the natural frequency of the platform in simulation and experiment. At the beginning of the free decay test, an initial displacement is applied to the platform. The initial displacement here is generalized and then released. The platform will return to the equilibrium position by the restoring force, then reciprocate, and will eventually become stationary.

The platform with tower conducted the free-decay test, and the result of free-decay test in numerical and experimental model is shown in Table 8, which also includes the simulation and experiment of previous studies $[20,21]$. There is a little difference in pitch and roll which might result from the small scale of the experimental model and the difference stays within 5 percent both in numerical and experimental model, which is acceptable.

Table 8. Natural period of model in experiment and simulation.

\begin{tabular}{cccccc}
\hline $\begin{array}{c}\text { No Mooring } \\
\text { System }\end{array}$ & $\begin{array}{c}\text { Experiment } \\
(\mathbf{1 : 1 4 4 )}\end{array}$ & $\begin{array}{c}\text { Experiment } \\
\text { (Full Scaled) }\end{array}$ & $\begin{array}{c}\text { OrcaFlex } \\
\text { (Full Scaled) }\end{array}$ & $\begin{array}{c}\text { FAST [21] } \\
\text { (Full Scaled) }\end{array}$ & $\begin{array}{c}\text { Experiment in } \\
\text { MARIN [21] (1:50) }\end{array}$ \\
\hline Heave & 1.5 & 18 & 16.7 & 17.3 & 17.5 \\
Roll & 2.366 & 28.39 & 25.6 & 26.7 & 26.9 \\
Pitch & 2.391 & 28.69 & 25.7 & 26.8 & 26.8 \\
\hline
\end{tabular}

\subsection{Conditions of Model Test and Simulation}

In this paper, there were regular wave test and irregular wave test in the model test and the conditions of each test are shown in Tables 9 and 10. The motion of rear and front platforms and the mooring lines tension of the multiline anchor were measured in two different tests. The incident angle of wind, wave and current in both tests are zero degree.

Table 9. Regular Wave Tests.

\begin{tabular}{cccc}
\hline Regular Wave & Wave Height $(\mathbf{m})$ & Wave Period $(\mathbf{s})$ & Wind Speed $(\mathbf{m} / \mathbf{s})$ \\
\hline RH72T16 & 7.2 & 16 & 0 \\
RH72T18 & 7.2 & 18 & 0 \\
RH72T20 & 7.2 & 20 & 0 \\
RH72T22 & 7.2 & 22 & 0 \\
RH72T24 & 7.2 & 24 & 0 \\
RH72T26 & 7.2 & 26 & 0 \\
\hline
\end{tabular}

Table 10. Irregular Wave Tests.

\begin{tabular}{cccccc}
\hline Irregular Wave & Wave Height $(\mathbf{m})$ & Wave Period $(\mathbf{s})$ & $\begin{array}{c}\text { Wind Speed } \\
(\mathbf{m} / \mathbf{s})\end{array}$ & $\begin{array}{c}\text { Current } \\
\text { Speed }(\mathbf{m} / \mathbf{s})\end{array}$ & Sea State \\
\hline JH6T10 & 6.10 & 10.4 & 60 & 1.2 & 10 -year return period \\
JH8T12 & 8.70 & 12.4 & 60 & 1.2 & 50-year return period \\
\hline
\end{tabular}

\section{Results and Discussions}

\subsection{Motion of Platform under Regular Wave Test}

There are six different periods of regular waves chosen in the experiment to measure the motion responses of pitch and heave, calculate the RAO and compare them with numerical results. The Response Amplitude Operator (RAO) is a value of engineering statistics which is mainly adopted for evaluating the dynamic response of a ship or floaters in the ocean. It is often obtained by different periods of regular wave and there is one or more than one peak which represents the resonance of floater under certain period. The RAO is defined as the ratio of the amplitude of motion responses and the amplitude of incident wave 


$$
R A O=\frac{Z_{a}}{\delta_{a}}
$$

where $Z_{a}$ is the amplitude of motion from crest to trough which is related to the position of the center of gravity, and $\delta_{a}$ is the incident wave height.

Figure 21 shows the scheme diagram of regular wave. In numerical simulation, the range of period is 12 to $30 \mathrm{~s}$ which belongs to long-period wave in Taiwan and the comparison between the experiment and numerical simulation is shown in Figures 22 and 23 .

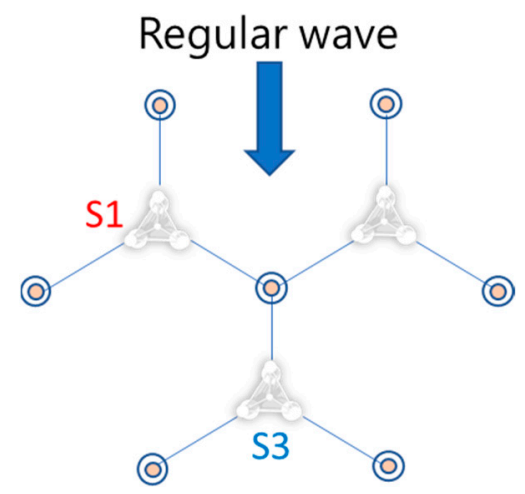

Figure 21. Scheme diagram of regular wave test.

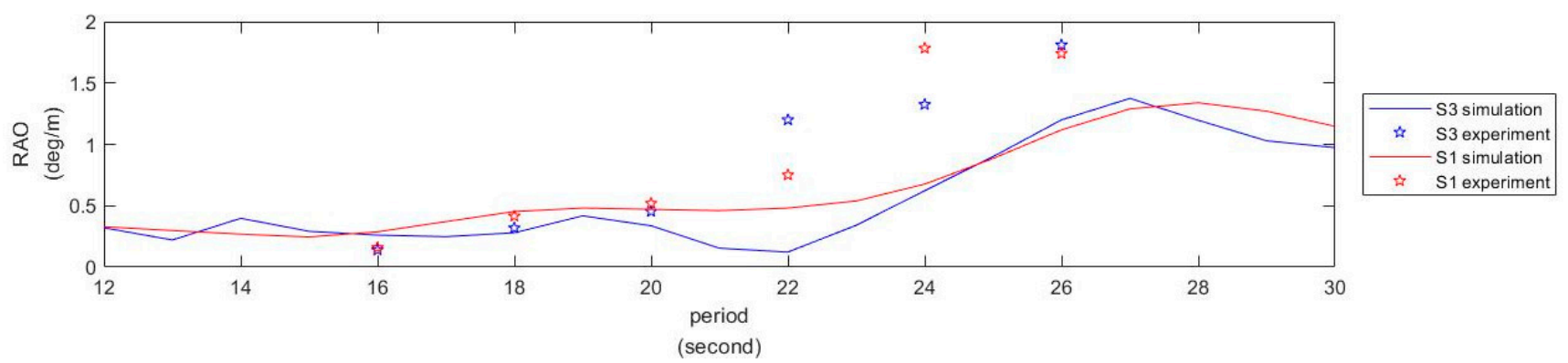

Figure 22. Comparison of pitch RAO between experiment and numerical simulation (without wind).

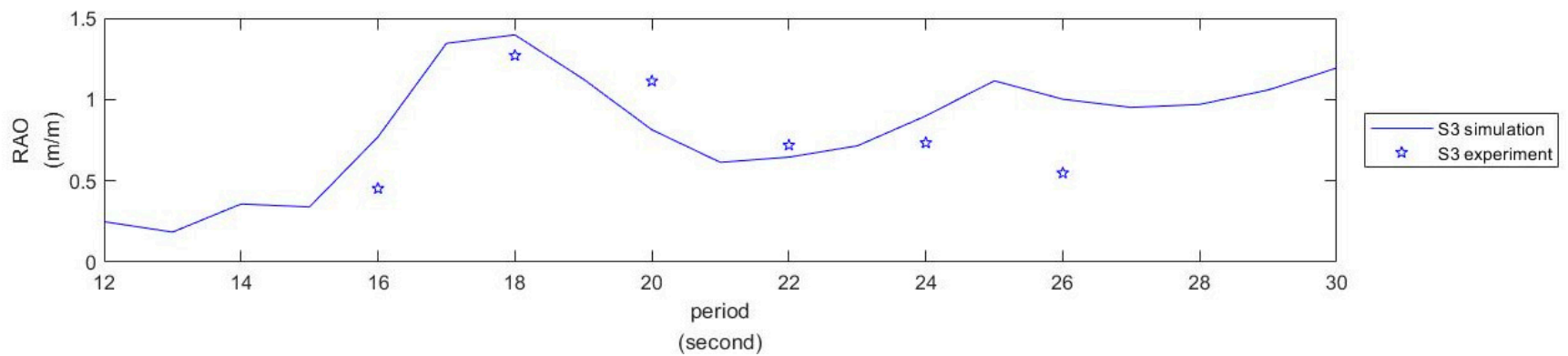

Figure 23. Comparison of heave RAO between experiment and numerical simulation (without wind).

In Figure 22, results obtained from the experiment and numerical simulation are represented by dotted and solid lines, respectively. No matter whether in experimental or numerical simulation results, S1 (front) mostly has a higher pitch RAO than S3 (rear) platform in the range of 16 to 26 seconds, although the magnitude of pitch RAO is a little higher in experiment. However, the trends of experiments and numerical simulation are approximate, there is still a little difference which the pitch RAO of long-period wave (22 to $26 \mathrm{~s}$ ) in experiments are higher than the one in numerical simulation. The difference might be resulted from the limited efficiency of wave absorption zone in the wave basin for long 
wave cases. In Figure 23, the results of experiment and numerical simulation are match with each other which both have a peak value at the natural period of heave.

\subsection{Motion of Platforms under Irregular Wave Test (with Wind and Current)}

Figure 24 shows the direction of conditions for wind, wave and current under irregular wave test. The pitch distribution of S1 and S3 under different conditions are shown in Figure 25 (experiment) and Figure 26 (numerical simulation), and the value of distribution is shown in Table 11 (experiment) and Table 12 (numerical simulation). In experiment, the pitch distribution of S3 and S1 mostly maintains within 0 to 5 degrees, and it is in line with the results of numerical simulation. No matter whether in experiment or numerical simulation, each case shows that the average pitch of S3 is higher than S1 (shown in Tables 11 and 12), and these results are different from the regular wave test which is because the wave period in regular wave test belongs to long-period wave (16 to $26 \mathrm{~s}$ ) rather than short-period wave (6 to $12 \mathrm{~s}$ ) which is in irregular wave test. Moreover, the average pitch angle of S3 and S1 is higher under a 10-year return period than a 50-year return period, which is because the rotation of platforms under 50-year conditions varies more dramatically than the one under 10-year conditions.

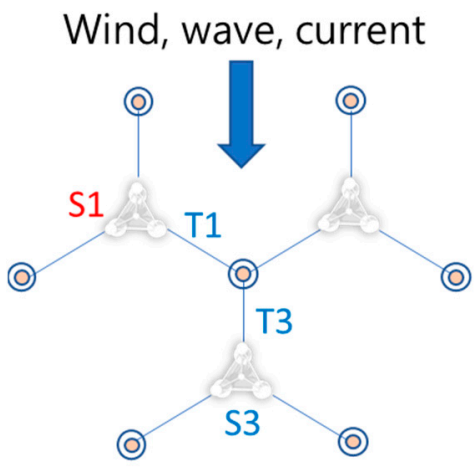

Figure 24. Scheme diagram of irregular wave test (with wind and current).
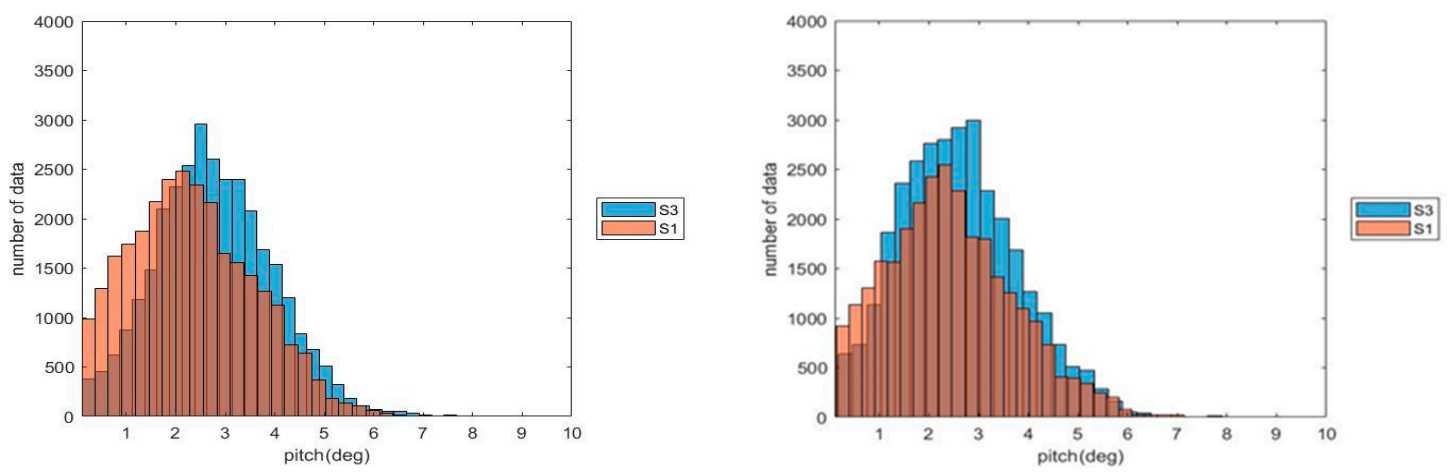

Figure 25. Pitch distribution of 10-year (left) and 50-year (right) return periods in experiment.
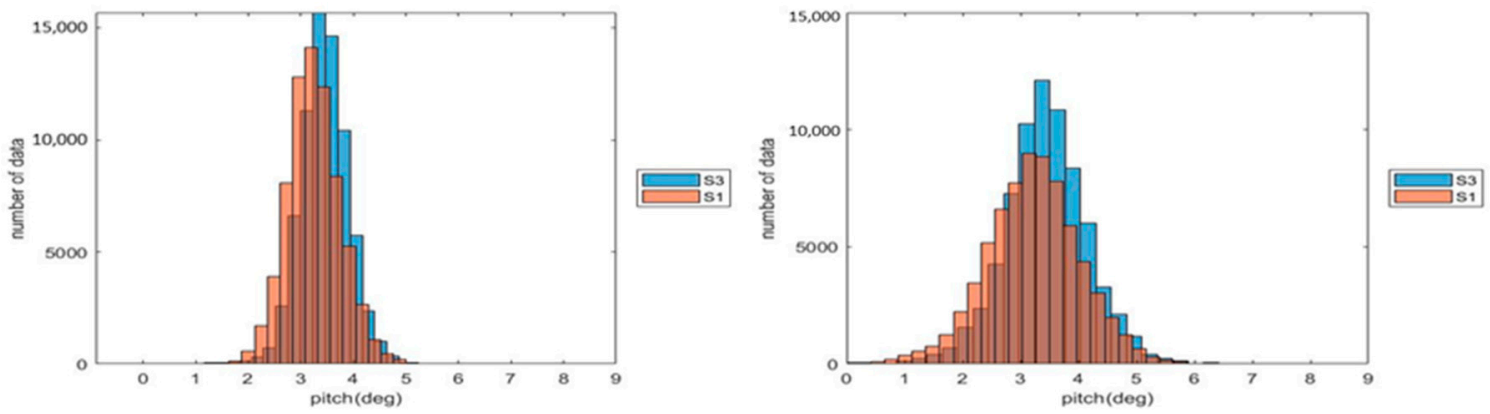

Figure 26. Pitch distribution of 10-year (left) and 50-year (right) return periods in numerical simulation. 
Table 11. Pitch distribution between S1 and S3 in experiment.

\begin{tabular}{cccccc}
\hline S3 (Experiment) & 10-Year return & 50-Year Return & S1 (Experiment) & 10-Year Return & 50-Year Return \\
\hline $0 \sim 5$ degree $(\%)$ & 93.9 & 92.6 & $0 \sim 5$ degree $(\%)$ & 91.6 & 90.1 \\
5 10 degree $(\%)$ & 3.79 & 3.75 & $5 \sim 10$ degree $(\%)$ & 2.15 & 3.83 \\
Average angle $\left({ }^{\circ}\right)$ & 2.71 & 2.50 & Average angle $\left({ }^{\circ}\right)$ & 2.27 & 2.37 \\
\hline
\end{tabular}

Table 12. Pitch distribution between S1 and S3 in simulation.

\begin{tabular}{cccccc}
\hline S3 (Simulation) & 10-Year Return & 50-Year Retsurn & S1 (Simulation) & 10-Year Return & 50-Year Return \\
\hline $0 \sim 5$ degree $(\%)$ & 99.9 & 98.5 & $0 \sim 5$ degree $(\%)$ & 99.8 & 98.7 \\
5 10 degree $(\%)$ & 0.02 & 1.42 & $5 \sim 10$ degree $(\%)$ & 0.11 & 1.21 \\
Average angle $\left({ }^{\circ}\right)$ & 3.45 & 3.43 & Average angle $\left({ }^{\circ}\right)$ & 3.25 & 3.21 \\
\hline
\end{tabular}

The time series of dimensionless heave and surge motion are shown in Figures 27 and 28. Amplitude and magnitude of S3 dimensionless heave motion do not change too much under different conditions either in experiment or numerical simulation. The maximum and average values of S3 dimensionless surge motion under 10-year return period are higher than those of 50-year return period, which is because the dimensional displacement scale of platform is approximate under two different conditions (shown in Tables 13 and 14).
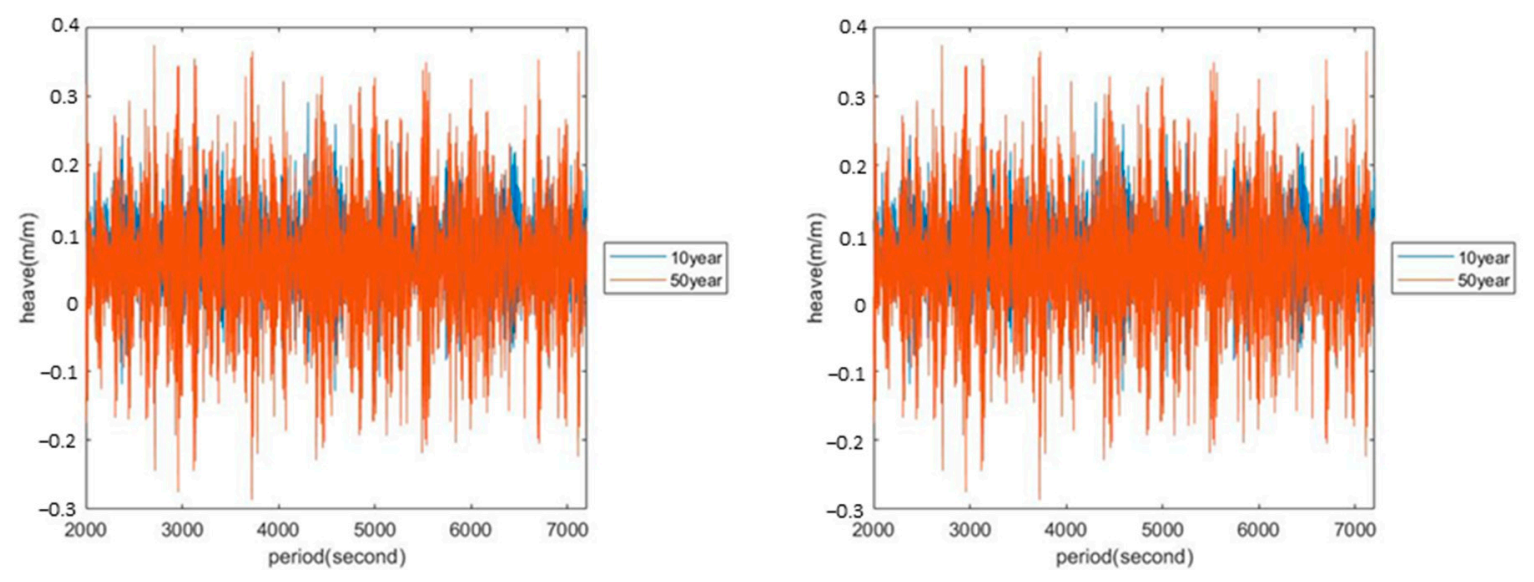

Figure 27. Time series of S3 heave motion under 10-year and 50-year return periods in experiment (left) and numerical simulation (right).
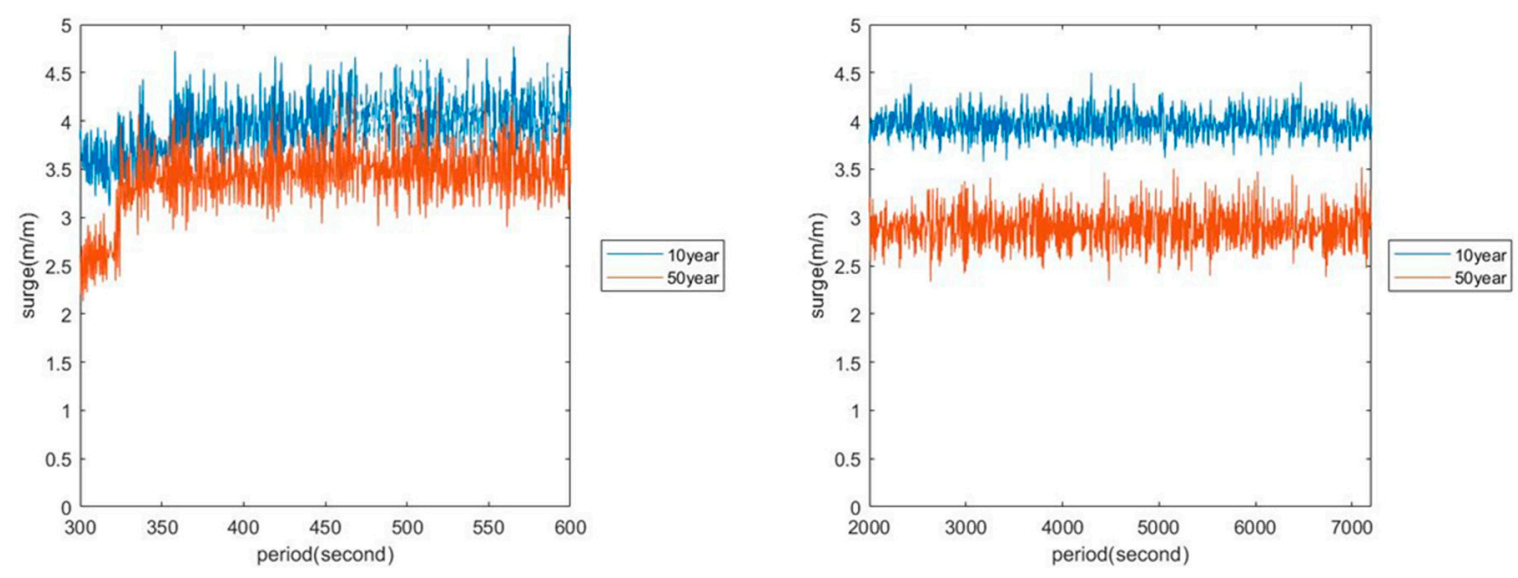

Figure 28. Time series of S3 surge motion under 10-year and 50-year return periods in experiment (left) and numerical simulation (right). 
Table 13. Dimensionless heave motion of S3 under different conditions in experiment and numerical simulation.

\begin{tabular}{ccccc}
\hline Heave $(\mathbf{m} / \mathbf{m})$ & $\begin{array}{c}\text { 10-Year Return Period } \\
\text { (Numerical } \\
\text { Simulation) }\end{array}$ & $\begin{array}{c}\text { 10-Year Return Period } \\
\text { (Experiment) }\end{array}$ & $\begin{array}{c}\text { 50-Year Return Period } \\
\text { (Numerical } \\
\text { Simulation) }\end{array}$ & $\begin{array}{c}\text { 50-Year Return Period } \\
\text { (Experiment) }\end{array}$ \\
\hline Average & 0.08 & 0.04 & 0.05 & 0.03 \\
Maximum & 0.29 & 0.30 & 0.36 & 0.32 \\
Standard deviation & 0.053 & 0.093 & 0.09 & 0.089 \\
\hline
\end{tabular}

Table 14. Dimensionless Surge motion of S3 under different conditions in experiment and numerical simulation.

\begin{tabular}{ccccc}
\hline Surge $(\mathbf{m} / \mathbf{m})$ & $\begin{array}{c}\text { 10-Year Return Period } \\
\text { (Numerical } \\
\text { Simulation) }\end{array}$ & $\begin{array}{c}\text { 10-Year Return Period } \\
\text { (Experiment) }\end{array}$ & $\begin{array}{c}\text { 50-Year Return Period } \\
\text { (Numerical } \\
\text { Simulation) }\end{array}$ & $\begin{array}{c}\text { 50-Year Return Period } \\
\text { (Experiment) }\end{array}$ \\
\hline Average & 3.97 & 4.01 & 2.80 & 3.50 \\
Maximum & 4.50 & 4.89 & 3.38 & 4.29 \\
Standard deviation & 0.12 & 0.29 & 0.17 & 0.49 \\
\hline
\end{tabular}

\subsection{Tension Analysis of Multiline Anchor System}

It is the most important part of the concept of multiline anchor since the feasibility and stability mostly depend on the tension of mooring line. The calculation of resultant force is shown in Figure 29 and the main force on the multiline anchor is from T3.

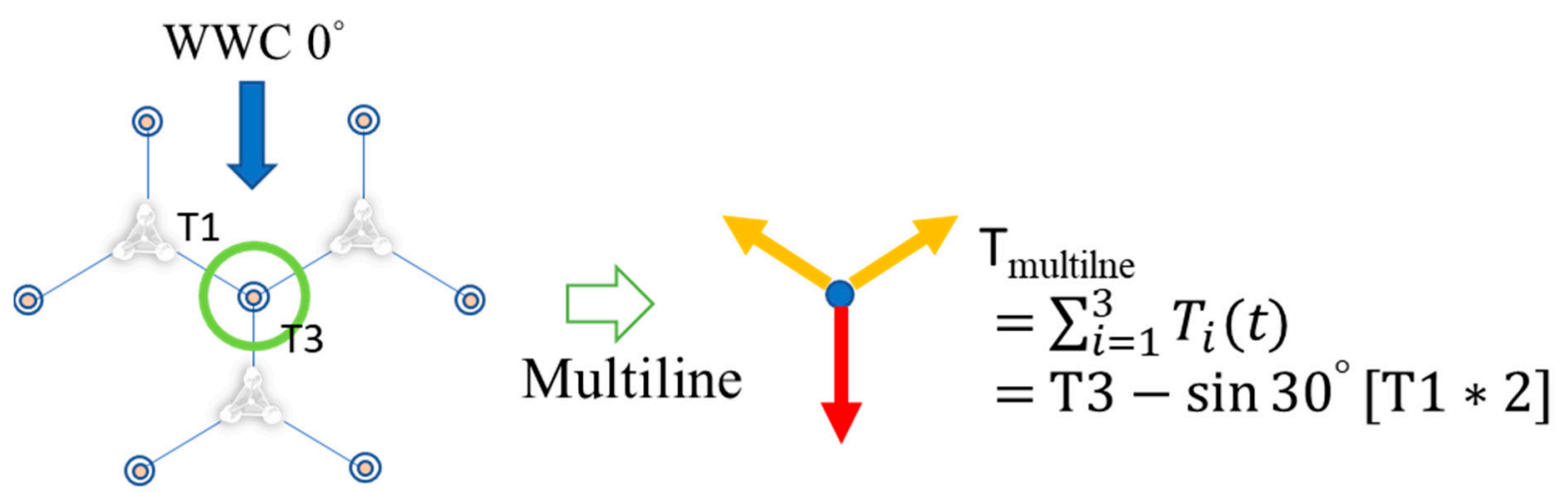

Figure 29. The mooring tension calculation for $\mathrm{T} 3$ and T-multiline.

The results of mooring tension are shown in Figures 30 and 31. The top and bottom of the boxplot represents maximum and minimum tension, and the middle of the box represents median of the results. In Figure 30, results for the median of T3 under the 10-year return period is quite approximate between numerical simulation and experiment and this is also the case for the results under the 50-year return period. However, the results from numerical simulation of T3 under the 50-year return period shows that the maximum tension occurs close to Minimum Breaking Load (MBL) and thus the optimization of mooring lines will be discussed in the next section. In Figure 31, the results for mooring tension of T-multiline is quite similar to that of T3 mooring tension since the direction of wind, wave, and current are all set as 0 degrees in the simulation, making the platform move backwards and, therefore, the mooring line tension of $\mathrm{T} 3$ becomes the dominant force acting on the multiline anchor. Moreover, owing to no viscous damping terms being considered in the numerical simulation, the maximum values of T3 and T-multiline obtained from numerical simulation are higher than those values from experiment. 


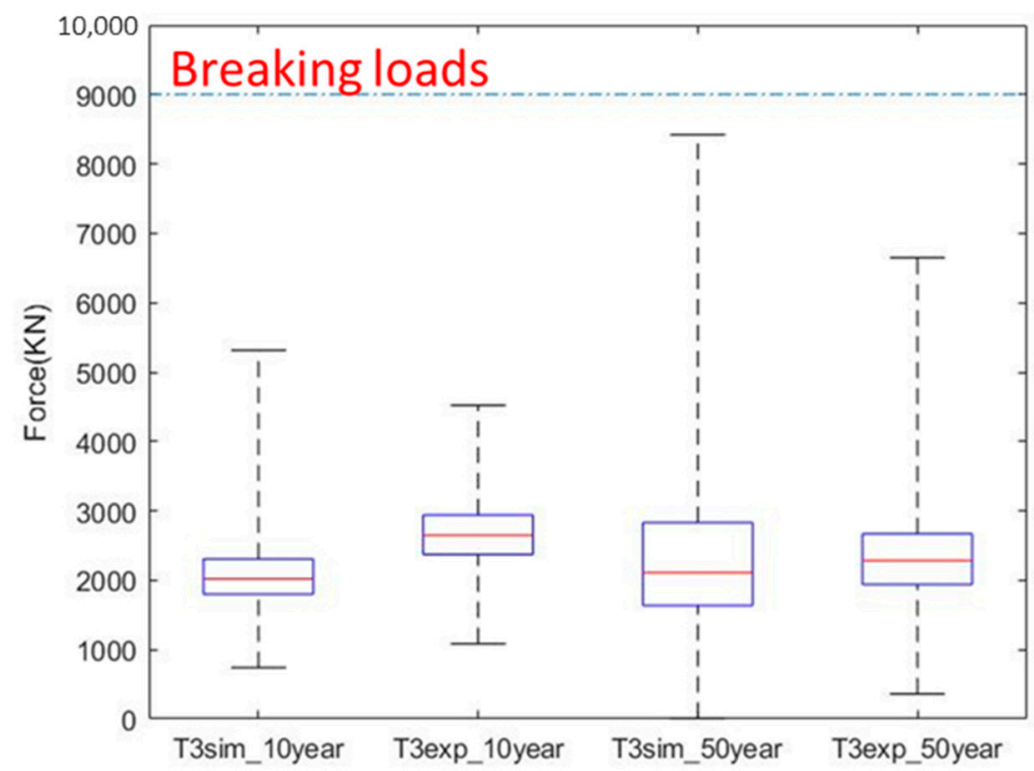

Figure 30. Boxplot of T3 under 10-year (left) and 50-year (right) return periods in experiment and numerical simulation.

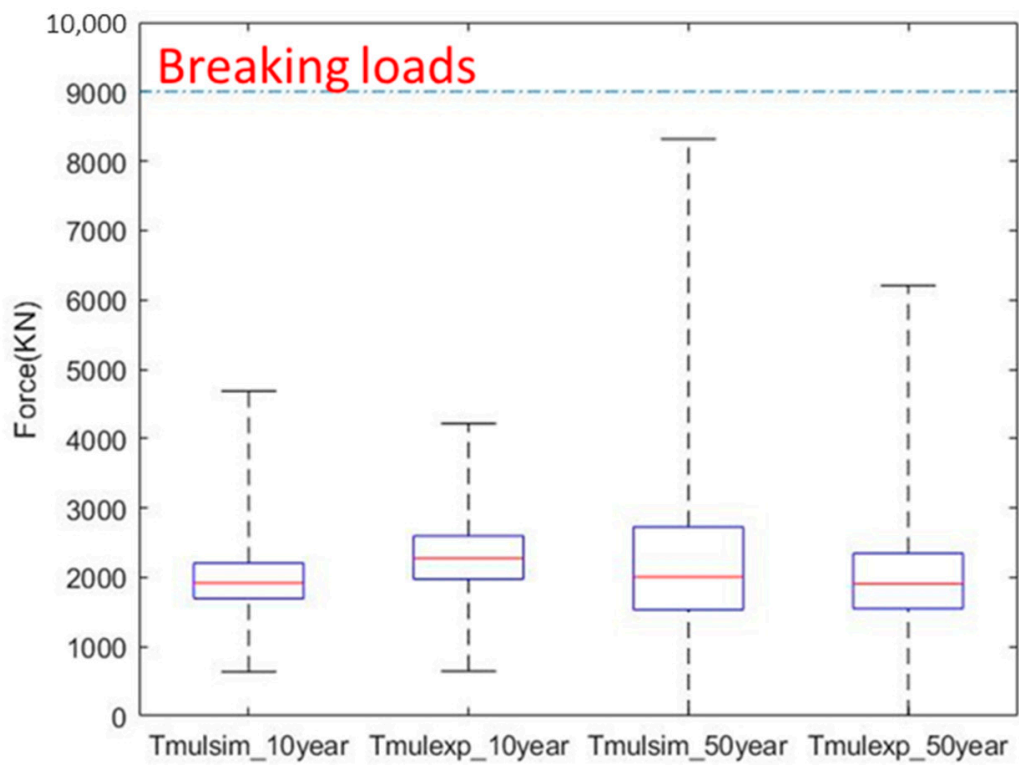

Figure 31. Boxplot of T-multiline under 10-year (left) and 50-year (right) return periods in experiment and numerical simulation.

\subsection{Mooring Line Optimization}

In Section 5.3, it shows that the tension of mooring lines not reaching up to the Minimum Breaking Load (MBL), but the maximum tension value under 50-year return period almost exceeding the MBL. Therefore, this section considered to change the diameter of mooring lines (shown in Table 15) for optimizing the motion of platforms and decreasing the tension on the fairlead and multiline anchor by using numerical simulation. For mooring line optimization, two more sea state conditions that wind turbines are operated are added. (shown in Table 16) 
Table 15. Characteristics of three different diameters of R4 mooring lines.

\begin{tabular}{cccc}
\hline $\begin{array}{c}\text { Diameter } \\
(\mathbf{R} 4)\end{array}$ & $\begin{array}{c}\text { Proof Load } \\
(\text { KN) }\end{array}$ & $\begin{array}{c}\text { Break Load } \\
\text { (KN) }\end{array}$ & $\begin{array}{c}\text { Unit Weight } \\
(\mathbf{k g} / \mathbf{m})\end{array}$ \\
\hline $95 \mathrm{~mm}$ & 6307 & 9001 & 179.6 \\
$135 \mathrm{~mm}$ & 11617 & 16578 & 362.7 \\
$175 \mathrm{~mm}$ & 17640 & 25174 & 609.4 \\
\hline
\end{tabular}

Table 16. Four different sea state conditions of irregular wave, wind and current.

\begin{tabular}{ccccccc}
\hline & Wind turbine & $\begin{array}{c}\text { Wave Height } \\
(\mathbf{m})\end{array}$ & $\begin{array}{c}\text { Wave Period } \\
(\mathbf{s})\end{array}$ & $\begin{array}{c}\text { Wind Speed } \\
(\mathbf{m} / \mathbf{s})\end{array}$ & $\begin{array}{c}\text { Current Speed } \\
(\mathbf{m} / \mathbf{s})\end{array}$ & Sea State \\
\hline JH1T5 & \multirow{2}{*}{ Operated } & 1.67 & 5.17 & 11.4 & 0.3 & Normal sea condition \\
JH5T9 & & 5.52 & 9.4 & 11.4 & 1.2 & Northeast monsoon \\
JH6T10 & Non-operated & 6.1 & 10.4 & 60 & 1.2 & $10-$ year return period \\
JH8T12 & & 8.7 & 12.4 & 60 & 1.2 & 50 -year return period \\
\hline
\end{tabular}

There is a design standard in DNV-ST-0119 [22] for floating offshore wind turbines, and the load design of mooring system is defined as:

$$
T_{d}=\gamma_{\text {mean }} \cdot T_{c, \text { mean }}+\gamma_{d y n} \cdot T_{c, d y n}
$$

where $T_{d}$ is the design tension, $T_{c, \text { mean }}$ is the characteristic mean tension of the time series, $\gamma_{d y n}$ is defined as the characteristic dynamic line tension of 50-year return period caused by low-frequency and wave-frequency motions and. $\gamma_{\text {mean }}$ and $T_{c, d y n}$ are load factors which is shown in Table 17.

For Ultimate Limit State (ULS), the design criteria is calculated as per the following equation:

$$
T_{d} \leq S_{C}
$$

where $S_{C}$ is 0.95 of minimum breaking load (MBL).

Table 18 shows that the class 1 and class 2 mooring lines do not meet the ULS design criteria proposed by DNV-ST-0119 under the $95 \mathrm{~mm}$ diameter. By contrast, the tension of the optimized mooring lines (135 $\mathrm{mm}$ and $175 \mathrm{~mm}$ ) both meet the regulation.

Table 17. Loads factor for ULS.

\begin{tabular}{cccc}
\hline Consequence Class & Type of Analysis of Wave Frequency Tension & $\gamma_{\text {mean }}$ & $\gamma_{\text {dyn }}$ \\
\hline 1 & Dynamic & 1.0 & 1.5 \\
2 & Dynamic & 1.4 & 2.1 \\
\hline
\end{tabular}

Table 18. Design line tension for ULS in irregular waves.

\begin{tabular}{cccc}
\hline Diameter & Class & $\boldsymbol{T}_{\boldsymbol{d}}(\mathbf{K N})$ & $\boldsymbol{S}_{C}(\mathbf{K N})$ \\
\hline \multirow{2}{*}{$95 \mathrm{~mm}$} & 1 & 8552 & 8551 \\
& 2 & 11,974 & 15,749 \\
$135 \mathrm{~mm}$ & 1 & 7496 & 23,915 \\
& 2 & 10,495 & \\
\hline
\end{tabular}

\section{Conclusions}

The multiline anchor is a new concept of multiple floating wind turbines and has been recently studied for applications in deep water. In a previous study, the deeper water (beyond $100 \mathrm{~m}$ ) has been considered and only the number of anchors have been taken into account in terms of cost reduction. Therefore, this paper not only measures the 
cost reduction of the marine space in a wind farm but also focuses on the difference of motion between the platforms and tension on multiline anchor in shallow water $(70 \mathrm{~m})$. Three OC4 DeepCwind platforms with NREL 5 MW wind turbines were carried out by numerical simulation (OrcaFlex) and 1:144 scaled-model experiment. After mutual verifications, there are good agreement between them, which includes trends of the motion and mooring tension. Furthermore, due to the space limitation of wave basin for using the small-scale model in this study, some small differences still occurred in pitch and surge motion compared with numerical simulation. In future studies, improvements are needed, by using the larger scaled experiment for the multiline anchor application. In the last section, optimization of the mooring design was implemented in numerical simulation to improve the stability and feasibility of multiline anchor.

The results obtained in this study are summarized as follows:

1. The concept of multiline anchor can not only reduce the number of anchors but also the space of a wind farm. Under different distances between three platforms, it shows about $24 \%$ reduction of wind farm configuration which is of benefit to the spatial planning.

2. The experimental results of regular wave test are compared to the numerical ones. It shows that there are different motions between front and rear platform under long-period wave both in experiment and numerical simulation.

3. In the irregular wave test, the results of pitch between the platforms did not have too much difference and it shows that the effect between platforms can be nearly neglected. Further research can focus more on the total anchor force in different mooring system under shallow water depth (ex.70 water depth).

4. The results of non-dimensional surge and heave motions of rear platform are similar in experiment and numerical simulation. As for the tension acting on the multiline anchor, it also has good correspondences, the medium of tension is similar and whatever the maximum value is, there are slight differences due to the small-scale limitation.

5. For the optimization of mooring lines through changing the diameters to $135 \mathrm{~mm}$ and $175 \mathrm{~mm}$, the design tension $\left(T_{d}\right)$ acting on the fairlead meets with the criteria under the mooring line diameters of $135 \mathrm{~mm}$ and $175 \mathrm{~mm}$.

Author Contributions: Conceptualization, R.-Y.Y. and Y.-H.C.; methodology, R.-Y.Y. and Y.-H.C.; software, R.-Y.Y. and Y.-H.C.; validation, R.-Y.Y. and Y.-H.C.; formal analysis, R.-Y.Y. and Y.-H.C.; in-vestigation, R.-Y.Y. and Y.-H.C.; resources, R.-Y.Y.; data curation, Y.-H.C.; writing—original draft preparation, Y.-H.C.; writing —review and editing, R.-Y.Y. and Y.-H.C.; visualization, R.-Y.Y. and Y.-H.C.; supervision, R.-Y.Y.; project administration, R.-Y.Y.; funding acquisition, R.-Y.Y. All authors have read and agreed to the published version of the manuscript.

Funding: This research was funded by Ministry of Science and Technology, Taiwan grant number MOST 110-2221-E-006-060-166-MY2.

Institutional Review Board Statement: This study did not involve humans or animals.

Informed Consent Statement: This study did not involve humans.

Data Availability Statement: This study did not report any data.

Acknowledgments: The authors are grateful for the support of the Ministry of Science and Technology in Taiwan, under the grant numbers MOST 110-2221-E-006-060-166-MY2.

Conflicts of Interest: The authors declare no conflict of interest.

\section{References}

1. Tacx, J. Floating Wind Structures and Mooring Types. 2019. Available online: https://www.energyfacts.eu/Energyfacts.eu (accessed on 12 February 2021).

2. Pillai, A.; Thies, P.R.; Johanning, L. Multi-Objective Optimization of Mooring Systems for Offshore Renewable Energy. 2017. Available online: https:/ / ore.exeter.ac.uk/repository/handle/10871/29194 (accessed on 12 February 2021). 
3. Ozmutlu, S. Anchor and Mooring Line Cost Estimates. In Proceedings of the 45th Annual Conference on Deep Foundations, Online, 27-30 October 2020. Available online: https:/ / www.researchgate.net/publication/345682287 (accessed on 12 February 2021).

4. Fontana, C.M.; Arwade, S.R.; DeGroot, D.J.; Myers, A.T.; Landon, M.; Aubeny, C. Efficient Multiline Anchor Systems for Floating Offshore Wind Turbines. In Proceedings of the ASME 2016 35th International Conference on Ocean, Offshore and Arctic Engineering, Busan, Korea, 19-24 June 2016; Volume 49972.

5. Diaz, B.D.; Rasulo, M.; Aubeny, C.P.; Fontana, C.M.; Arwade, S.R.; DeGroot, D.J.; Landon, M. Multiline anchors for floating offshore wind towers. In Proceedings of the OCEANS 2016 MTS/IEEE Monterey, Monterey, CA, USA, 19-23 September 2016; pp. 1-9.

6. Fontana, C.M.; Arwade, S.R.; DeGroot, D.J.; Hallowell, S.T.; Aubeny, C.; Landon, M.; Ozmultu, S. Multiline anchors for the OC4 semisubmersible floating system. In Proceedings of the 27th International Ocean and Polar Engineering Conference, San Francisco, CA, USA, 25-30 June 2017.

7. Hallowell, S.T.; Arwade, S.R.; Fontana, C.M.; DeGroot, D.J.; Aubeny, C.P.; Diaz, B.D.; Myers, A.T.; Landon, M.E. System reliability of floating offshore wind farms with multiline anchors. Ocean Eng. 2018, 160, 94-104. [CrossRef]

8. Fontana, C. A Multiline Anchor Concept for Floating Offshore Wind Turbines. Ph.D. Thesis, University of Massachusetts Amherst, Amherst, MT, USA, February 2019.

9. Fontana, C.M.; Hallowell, S.T.; Arwade, S.R.; DeGroot, D.J.; Landon, M.E.; Aubeny, C.P.; Diaz, B.; Myers, A.T.; Ozmutlu, S. Multiline anchor force dynamics in floating offshore wind turbines. Wind. Energy 2018, 21, 1177-1190. [CrossRef]

10. Offshore Wind Power Project Environmental Impact Statement; Preparatory Office of Taiwan First Wind Power Co., Ltd.: Taipei, Taiwan, 2017.

11. Lu, H.-H.; Yang, M.-H.; Chiu, K.-R. Practical application analysis of suspended line on anchor system. In Proceedings of the 34th Ocean Engineering Conference, National Cheng Kung University, Tainan, Taiwan, November 2012.

12. Ma, K.-T.; Wu, Y.; Stolen, S.F.; Bello, L.; der Horst, M.V.; Luo, Y. Mooring Designs for Floating Offshore Wind Turbines Leveraging Experience From the Oil \& Gas Industry. In Proceedings of the International Conference on Ocean, Offshore, and Arctic Engineering (OMAE), Online, 21-30 June 2021; Volume 85116.

13. Ma, K.-T.; Luo, Y.; Kwan, T.; Wu, Y. Mooring System Engineering for Offshore Structures; Elsevier BV: Amsterdam, The Netherlands, 2019.

14. Orcina. OrcaWave Help. 2021. Available online: https://www.orcina.com/webhelp/OrcaWave/Default.htm (accessed on 12 February 2021).

15. Orcina. OrcaFlex Help. 2021. Available online: https://www.orcina.com/webhelp/OrcaFlex/Default.htm (accessed on 12 February 2021).

16. Jonkman, J.M.; Hayman, G.J.; Jonkman, B.J.; Damiani, R.R.; Murray, R.E. AeroDyn v15 User's Guide and Theory Manual; Technical Report; National Renewable Energy Laboratory (NREL): Golden, CO, USA, 2015. Available online: https://www.nrel.gov/ wind/nwtc/assets / pdfs/aerodyn-manual.pdf (accessed on 1 September 2015).

17. Khan, N.U.; Ansari, K.A. On the dynamics of a multicomponent mooring line. Comput. Struct. 1986, 22, 311-334. [CrossRef]

18. Jonkman, J.; Butterfield, S.; Musial, W.; Scott, G. Definition of a 5-MW Reference Wind Turbine for Offshore System Development; Technical Report NREL/TP-500-38060; National Renewable Energy Laboratory: Golden, CO, USA, 2009.

19. International Electrotechnical Commission. Wind Energy Generation Systems_Part 1: Design Requirements; International Electrotechnical Commission: Geneva, Switzerland, 2019.

20. Robertson, A.; Jonkman, J.; Masciola, M.; Song, H.; Goupee, A.; Coulling, A.; Luan, C. Definition of the Semisubmersible Floating System for Phase II of OC4; NREL Technical Report; NREL/TP-5000-60601; National Renewable Energy Laboratory (NREL): Golden, CO, USA, 2014.

21. Coulling, A.J.; Goupee, A.J.; Robertson, A.; Jonkman, J.; Dagher, H.J. Validation of a FAST semi-submersible floating wind turbine numerical model with DeepCwind test data. J. Renew. Sustain. Energy 2013, 5, 023116. [CrossRef]

22. DNV. DNV-ST-0119 Floating Wind Turbine Structures. 2018. Available online: https://rules.dnv.com/docs/pdf/DNV/ST/2018 -07/DNVGL-ST-0119.pdf (accessed on 1 July 2018). 